NBER WORKING PAPER SERIES

REMEDIES FOR SICK INSURANCE

Daniel L. McFadden

Carlos E. Noton

Pau Olivella

Working Paper 17938

http://www.nber.org/papers/w17938

\author{
NATIONAL BUREAU OF ECONOMIC RESEARCH \\ 1050 Massachusetts Avenue \\ Cambridge, MA 02138 \\ March 2012
}

McFadden acknowledges support from the E. Morris Cox fund at the University of California, Berkeley, the Presidential fund at USC, the Schaeffer Center for Health Economics and Policy at USC, and National Institute on Aging (NIA) grants No. P01 AG005842 to the NBER and No. RC4 AG039036 to USC; Olivella acknowledges support from the Ministerio de Educación y Ciencia, project ECO2009-07616. We thank Peter Diamond, Mike Rothschild, Victor Fuchs, and Jonathan Gruber for useful comments. All conclusions of this research are solely those of the authors, and not necessarily those of the supporting institutions or of the individuals cited. The views expressed herein are those of the authors and do not necessarily reflect the views of the National Bureau of Economic Research.

NBER working papers are circulated for discussion and comment purposes. They have not been peerreviewed or been subject to the review by the NBER Board of Directors that accompanies official NBER publications.

(C) 2012 by Daniel L. McFadden, Carlos E. Noton, and Pau Olivella. All rights reserved. Short sections of text, not to exceed two paragraphs, may be quoted without explicit permission provided that full credit, including $\odot$ notice, is given to the source. 
Remedies for Sick Insurance

Daniel L. McFadden, Carlos E. Noton, and Pau Olivella

NBER Working Paper No. 17938

March 2012

JEL No. D4,D62,I13,I18

\begin{abstract}
This expository paper describes the factors that contribute to failure of health insurance markets, and the regulatory mechanisms that have been and can be used to combat these failures. Standardized contracts and creditable coverage mandates are discussed, along with premium support, enrollment mandates, guaranteed issue, and risk adjustment, as remedies for selection-related market damage. An overall conclusion of the paper is that the design and management of creditable coverage mandates are likely to be key determinants of the performance of the health insurance exchanges that are a core provision of the PPACA of 2010. Enrollment mandates, premium subsidies, and risk adjustment can improve the stability and relative efficiency of the exchanges, but with carefully designed creditable coverage mandates are not necessarily critical for their operation.

Daniel L. McFadden

University of California, Berkeley

Department of Economics

549 Evans Hall \#3880

Berkeley, CA 94720-3880

and NBER

mcfadden@econ.berkeley.edu

Carlos E. Noton

Department of Economics

University of Warwick

Coventry

Post Code: CV4 7AL

United Kingdom

C.Noton@warwick.ac.uk

Pau Olivella

Departament Economia i Historia Economica

Universitat Autonoma de Barcelona

08193 Cerdanyola del Valles

Barcelona

Spain

and Barcelona GSE

pau.olivella@uab.es
\end{abstract}




\title{
REMEDIES FOR SICK INSURANCE
}

\author{
Daniel McFadden, Carlos Noton, Pau Olivella \\ March 2012
}

\section{BACKGROUND}

Heterogeneity in consumer tastes and needs, and in cost and quality of goods and services, are ubiquitous features of resource allocation. When these variations are observed, competitive markets price, sort, and match them efficiently. For example, in a market in which private information cannot improve upon information available to all participants in predicting the expected costs and benefits from contracts for goods and services, such as maintenance contracts on furnaces, competition will price these contracts at their expected marginal costs to the sellers, buyers will chose among contracts and sellers to maximize their expected values, and market efficiency will be achieved. An important feature of these efficient contracts are clauses, offered and priced, that spell out and limit actions of the contracting parties in response to downstream events and experience.

When market participants have informative private information on states or actions that affect costs or values, this can interfere with market incentives, and cause markets to operate inefficiently, or even unravel. For example, if firms providing furnace maintenance vary in reliability, and this is difficult for buyers to assess, price may be used as a signal of quality, distorting its role as a signal of scarcity. Further, when government intervenes to promote fairness in markets that are not delivering socially acceptable outcomes, this can have the unintended side effect of introducing problems similar to those caused by private information.

In well-functioning insurance markets where competitive underwriting can price contracts at their actuarial cost based on public information, without adverse effects from private information of buyers, risk-adverse consumers will be able to buy insurance contracts at close to their individualized actuarial values. In the United States, health insurance markets fail to achieve this efficient competitive market ideal. A significant portion of the population is uninsured or under-insured, either because they are denied coverage, or because they believe that the contracts available to them in the market are actuarially unattractive or contain clauses that make their promised benefits risky. ${ }^{1}$ The health cost of incomplete coverage is substantial. Tardy diagnoses and inconsistent follow-ups are more common among the

\footnotetext{
${ }^{1}$ See Card-Dobles-Maestas (2008), Gruber (2008), Heiss-McFadden-Winter (2009).
} 
uninsured, and these exacerbate chronic conditions and lead to complications. In comparison with other countries, the United States ranks 25th in the survival rate from age 15 to age 60, which impacts the population of workers and young parents whose loss is a substantial cost to families and to the economy. ${ }^{2}$ If the U.S. could raise its survival rate for this group to that of Switzerland, a country that has mandatory standardized coverage offered by private insurers, this would prevent more than 190,000 deaths per year. The elderly in the United States aged 65 and older do have universal coverage under the Medicare program, with prescription drug coverage (Medicare Part D) added in 2006. This may explain the somewhat better comparative performance of the United States for seniors, a rank of 14th in life expectancy at age 65. Since the U.S. has a population that at retirement has the poorest health in the developed world, this is a medical accomplishment, but it is very costly - U.S. health expenditures per capita are 50 percent higher than those in any other country. Causes other than health insurance market failure contribute to the shortcomings of the health care delivery system in the United States, but the way health insurance is organized is one of the most striking differences in provision of health care in the United States and other developed countries.

Major contributors to health insurance market failure are (1) private information on states leading to adverse selection and passive moral hazard, (2) private information on actions leading to active moral hazard, (3) performance risk, (4) inefficient screening and signaling, (5) conflicts between social sentiment and competitive underwriting, (6) consumer misperception of risk, (7) market concentration, and (8) weak and inconsistent incentives induced by government intervention and regulation. Contracts offered in health insurance markets can vary on four primary dimensions: scope of conditions covered; benefit design that determines the share of losses uncovered, or copayments; levels of risk classification, reclassification, and screening based on available information and experience; and price (premium). Private information and other contributing factors can lead to wasteful competition on the first three of these dimensions, and to failure of price competition to guide efficient resource allocation.

This expository paper discusses regulatory mechanisms that can limit market damage from the factors listed above. We first define the factors, and list the most common regulatory mechanisms. After that, we concentrate particularly on the use of standardized contracts and creditable coverage standards, guaranteed issue, premium subsidies, and enrollment mandates to control adverse selection and channel competition to prevent health insurance market failure. These topics are also addressed in a more technical companion paper, McFadden-Noton-Olivella (2012). The term “creditable coverage” has a specific legal definition under the 2003 Medicare Prescription Drug, Improvement, and Modernization Act as an

\footnotetext{
2 These statistics are based on World Health Organization data for 2006, and U.S. Census data on population by age in 2006.
} 
insurance contract that is actuarially at least as favorable as a Standard contract specified by Medicare, but here we will use the term generically to denote regulatory restrictions on (minimum) conditions covered, (minimum) benefit designs, and (maximum) copayment rates. "Guaranteed issue”, also termed "open enrollment”, requires sellers to accept all purchase offers from consumers meeting announced contract conditions. "Premium subsidies" are government-provided consumer vouchers or seller subsidies. "Enrollment mandates” are legal requirements that consumers buy coverage. This paper concludes with a broader commentary on regulatory mechanisms for health care finance and its interaction with the overall problem of managing health care. We often refer to the United States health system, but the issues of health care finance are global, and many of the problems of resource allocation discussed here also arise in centrally administered single-payer systems; see Olivella and Vera-Hernandez (2012).

1.Private Information, Adverse Selection, Passive Moral Hazard: It has long been recognized that in markets where the quality is not easily distinguished so that various qualities trade at a common price, sellers have an incentive to offer lower-quality products whose cost is below the market price, and withhold higher-quality products whose cost is above the market price. Then the average quality of goods in the marketplace is lower than that potentially available, and the market may unravel from the top, fracturing into a spectrum of contracts whose attributes are distorted to avoid pooling with lower-quality products, or collapsing in a "death spiral" in which only the lowest quality products trade. Perhaps the oldest surviving comment on this phenomenon is in Aristophanes' comedy “The Frogs” in 405BC, where bad politicians driving good ones out of the political marketplace is compared to adulterated coins driving pure ones out of circulation. The impact of adverse selection on the debasement of money is enshrined in Gresham's law, “bad money drives out good”, stated variously by Copernicus (1519), Gresham (1558), and Walford (1881). The modern recognition that adverse selection can lead to unraveling of a variety of contemporary markets, including products such as used cars, workers in the labor force, and health insurance, dates from the contribution of Akerlof (1970). Belli (2001) gives a succinct description of the impact of adverse selection in health insurance markets: “... each individual chooses among the set of contracts offered by insurance companies according to his/her expected probability of using health services. In brief, those who foresee an intense use of health services will tend to choose more generous plans than those who expect a more limited use of them. In the extreme, for each premium and degree of coverage, those who will decide to purchase that particular health insurance contract are those who expect to have health expenditure greater or equal to the premium paid. Then, whatever the premium, the insurance company may end up with a loss on each customer.” 
While adverse selection characterized by Belli focuses on heterogeneity in the probability of illness, another dimension of selection is passive moral hazard where heterogeneity in the severity of illness is private information; this is also termed “ex post” moral hazard (Zwifel-Breyer-Kiffman, 2009, Sect. 6.4.2). Then an insurer cannot observe or verify severity, and cannot limit coverage to the most cost-effective treatment. Consequently more costly treatments may be selected than would be necessary if illness severity were public information.

There is a large literature on selection effects, much of it related to insurance markets. ${ }^{3}$ In practice, the extent to which an insurance market is damaged by selection will decrease when buyers are more risk averse, when their expectations are inaccurate so that their choices are poorly related to actual risk, and when they overstate the dispersion of possible future outcomes. If the degree of risk aversion is negatively correlated with health risk, adverse selection is blunted because the healthy are willing to buy policies for risk protection even though they perceive a heavy load. There is evidence for advantageous selection in some health insurance markets such as long-term care insurance where the risks involved are ambiguous and remote in time. ${ }^{4}$ However, Heiss, McFadden, and Winter (2010) find the opposite pattern in the market for Medicare Part D insurance - risk aversion does not seem to play a major role in consumer choice, and the uninsured are mostly low-risk healthy consumers with low education and incomes. This pattern may be a reflection of overconfidence by consumers of the predictability of future drug needs. In the general private health insurance market for individuals, screening and rejections based on observables that are correlated with private information on health risk may disguise the consequences of adverse selection, so that relatively high insurance enrollment rates among the healthy are due to supply-side rejections of the unhealthy rather than a negative correlation of risk aversion and health risk. Then market management of risk can be quite inefficient even if there is no direct evidence of insurance enrollment rates varying with health risk.

\footnotetext{
${ }^{3}$ Radner (1968, 1970), Akerlof (1970), and Diamond (1978) discuss the role of information in formation of markets. Feldstein (1973), Pauly (1974), Rothschild and Stiglitz (1976), Spence (1976), Riley (1975, 1979), Wilson (1979, 1980), Cutler and Reber (1998), Pauly and Nicholson (1999), Cutler and Zeckhauser (2000) Abbring et al (2003), Bajari et al (2006), Chiappori et al (2006), Olivella and Vera-Hernández (2007, 2010), Heiss-McFadden-Winter (2007, 2008, 2009, 2010), Gruber (2008), and Chade and Schlee (2011) discussions information in the context of health insurance.

${ }^{4}$ See Cardon and Hendel (2001), de Meza and Webb (2001), Finkelstein and McGarry (2003), Finklestein-Poterba (2004), Mahdavi (2005), Chiappori (2000), Chiappori et al (2006), Fang, Keane, and Silverman (2006), De Donder and Hindriks (2006), Cutler, Finkelstein, and McGarry (2008), and Buchmueller (2008). When risk-taking behavior is considered in a life-cycle setting, it is difficult to distinguish the effects of static tastes for risk and the life-cycle consequences of current risks. For example, people in poor health face high mortality risk, which reduces the probability of extended life with restricted consumption, and reduces the incentive to protect current assets. Consequently, people in poor health may be more tolerant of risk not because they are less risk-averse, but rather because the risks they face have different life-cycle implications.
} 
2.Unobservable Action, Active Moral Hazard: Consumers, providers, and insurers entering a health insurance contract can be viewed as principals and agents. The insurer can imperfectly discriminate avoidable and unavoidable risk-taking by the consumer, and consequently cannot easily categorize risk classes and penalize unnecessary risk-taking, an active or “ex ante” moral hazard. Then, the consumer's incentive for actions that avoid risks is diluted. Further, the insurer and the consumer can imperfectly discriminate the accuracy, efficacy, and prospective costs of diagnoses and treatments, so that the provider's and consumer's incentives to avoid unproductive or costly procedures are diluted, another active moral hazard. The impact of active moral hazard on principal-agent contracts, and co-payment, capitation, outcome-based compensation, and other mechanisms to mitigate its effect, are discussed in an extensive literature. $^{5}$

3.Performance Risk: Insurance contracts have the property that enrollment and payment of premiums come first, and health events and contingent benefit payments come later. With limited information and consumer inattention, insurers have incentives to shirk the payment of benefits through ambiguous contact language and legal stratagems that make contract enforcement costly. In addition, there is a risk of default by the insurer due to insufficient provision for benefit outlays, and due to systemic risk. The result is that receipt of contingent benefits is not risk-free to the buyer, reducing the attractiveness of an insurance contract even if it is nominally actuarially appealing. Performance risk is also called counter-party, credit, or default risk, and is currently a major issue in regulation of markets for financial insurance. ${ }^{6}$ Note that imperfect discrimination of performance risk may induce adverse selection, with low-cost, poorly-capitalized insurers driving higher-cost, better-capitalized ones out of the market. Control of performance risk has been a traditional goal of State insurance regulation in the United States.

4.Inefficient Screening: When consumers have private information on their health, and this induces adverse selection, the response of underwriters will be to categorize consumers into risk classes on the basis of observable information, and offer and price contracts by risk class. In some cases, insurers may refuse to offer coverage, a practice termed "lemon dropping" or "red-lining". ${ }^{7}$ Risk classification is typically based on insurance, medical, employment, and demographic histories of consumers and their kin.

${ }^{5}$ Clark (1895), Walford (1881), Crosby (1905), Pauly (1974), Arrow (1968), Spence and Zeckhauser (1971), Grubel (1971), Feinstein (1973), McGuire (2000), Fagart and Kambla-Chopin (2006), Zweifel, Breyer, and Kifmann (2009).

${ }^{6}$ Kilburn (1904), Hodgeman (1960), Clark (1976), Holmstrom (1979), Agarwal and Ligon (1998), Duffy and Singleton (2003), and Mahul and Wright (2004).

${ }^{7}$ Market failure in which consumers with some health histories are refused coverage at any price may come from restrictions on competitive underwriting, or may be a symptom of market unraveling due to adverse selection. 
Consumers then have incentives to misrepresent or burnish their histories to understate their risks. While risk classification is a natural part of underwriting, when screening and signaling responses are costly, they effectively increase the price of insurance contracts and render them actuarially less attractive. Screening can particularly distort resource allocation when insurers refuse coverage because individuals have earlier refusals or prior claims, as this can chill the market, discouraging individuals from applying for insurance or filing claims for losses, a form of active moral hazard. Competition and restrictions on collusion may increase the burden of screening, as insurers try to meet or beat the screening effectiveness of their rivals in order to survive. ${ }^{8}$

5.Conflicts of Social Sentiment and Competitive Underwriting: Consumers and society have difficulty refusing or withholding treatments after bad health outcomes are realized. For example, actuarially fair health insurance is extremely expensive for a consumer who has kidney failure or AIDS, but social sentiment is that this consumer is nevertheless entitled to access to treatment at affordable cost. Social sentiment for such ex post equity often conflicts with competitive underwriting. As a consequence, public sentiment often supports regulation of insurance and provider markets to address inequities. For example, insurers may be forbidden to base underwriting on race or gender, forbidden to set premiums or restrict coverage based on pre-existing conditions, forbidden to include rescission clauses in their contracts, and mandated to cover specified conditions. These regulations have the direct effect of mitigating market outcomes deemed unfair to higher-risk consumers, although they may be undercut if insurers can offer menus of contracts that fracture demand; see Finklestein et al (2009).

If regulation requires that the insurer offer unsubsidized coverage to high-risk consumers at less than actuarial value, an unintended consequence is that in order to survive in the market, insurers must offer premiums that are actuarially unfair to low-risk consumers. This induces adverse selection if low-risk consumers then choose to be uninsured, and can cause unraveling; see Buckmueller (2008). Legal limits on competitive risk classification, or price ceilings established legally or chosen to forestall legal challenge, give insurers incentives to screen and accept or reject buyers on the basis of observables that are correlated with risk, exclude coverage for pre-existing conditions when this is not prohibited to discourage enrollment by high-risk consumers, and reject potentially high-risk consumers outright when open enrollment is not enforced. The result may be large numbers of rejections and exclusions, leaving many consumers uninsured or under-insured. The apparent pattern in the United States where the most healthy have the

\footnotetext{
${ }^{8}$ The influence of screening and signaling on market outcomes has been studied by Spence $(1974,1976,1978)$, Riley (2002), and Buchmueller (2008). Community-rating systems to reduce the costs and selection effects of individual screening have been studied by Pauly (1970), Neuhaus (1995), and Encinosa (2001).
} 
highest share insured may arise because the healthy are more risk averse, but may also be due to higher rates of rejections and exclusions for the less healthy.

When social sentiment leads to mandates that hospitals and providers treat the critically ill even if they are unable to pay, poor consumers may choose this “insurance of last resort” unless premium subsidies or enrollment mandates nudge them into the private insurance market. The cost of their care is then borne by society through increased hospital fees. These fees are either subsidized by government, or eventually appear in increased insurance premiums that make contracts less actuarially attractive and exacerbate adverse selection. In general, effective imposition of fairness constraints without inducing adverse selection will require social intervention through public subsidies or direct market management, and interpersonal transfers that are contingent on circumstance and behavior.

6.Consumer Misperceptions of Risk: The standard treatment of selection assumes that the private information of consumers is accurate. However, beliefs and health choices of consumers are not necessarily fully rational or self-protective; see Card et al (2008), Heiss-McFadden-Winter (2010), Abaluck and Gruber (2011). An additional dimension of selection arises when unobserved individual risk is filtered through consumer perceptions that are not completely realistic. Two well-documented features of consumer behavior are over-optimism, manifest in discounting of the probability of adverse future events and underestimation of risks, and over-confidence (certitude) regarding ability to predict outcomes. Contrary to the assumptions of rational expectations theory, there is little market discipline for these beliefs in the case of future health events - while poor choices based on misperceptions may be punished in the market, the punishment is often not certain, prompt, or repetitive enough to train expectations to be rational. Consumers with the behavioral tendencies of optimism and certitude are likely to perceive insurance contracts as less fair than actuarial reality, and are likely to undervalue the reduction in risk the contracts offer. The result may be "knife-edge" insurance choices in which in the extreme consumers will buy only actuarially favorable contracts that are unprofitable for insurers. In summary, behavioral consumers may view insurance contracts as entitlements rather than as protection against risk, and feel cheated if benefits received do not come close to balancing premiums. If perceived risks are strongly positively correlated with true risks, then both over-optimism and over-confidence will exacerbate adverse selection, with only the truly most risky buying insurance. Private information does not distort the market if consumers fail to act upon it, or if perceived and actual risk are uncorrelated.

7.Market Concentration: The organization of health insurance suppliers can have a significant influence on the degree of loading of insurance contracts, the viability of contracts offered, and the burden 
of screening. Competition will tend to drive premiums down to the costs of offered contracts, but can exacerbate adverse selection through a "race to the bottom" in contract coverage, or costly screening, as competitors battle in these dimensions to attract lower-risk consumers and lemon-drop high-risk ones. Rents accruing to oligopolistic insurers will discourage the lowest-risk consumers from buying their contracts. However, insurers in a concentrated market do have more tools to combat adverse selection, through limiting the types of contracts offered, cross-subsidizing contracts to achieve a viable menu, and avoiding competitive risk classification; e.g., a monopolistic insurer designing a menu of contract offerings has to worry about one contract cannibalizing another, but not about a rival offering contracts that through screening can cherry pick or cream-skim the lowest-risk purchasers of an existing contract that are the least costly to serve; see Johnson (1977), Olivella and Vera-Hernandez (2007).

One feature of the American health insurance market, which is quite concentrated, is that the major insurers use their market power to bargain for discounts from providers, medical device makers, and pharmaceutical companies. Insured consumers benefit from this consequence of concentration to the extent that these cost savings are passed through. These price differences also make self-insurance relatively less attractive for the healthy, inducing increased enrollment and lower average payout rates in the insured population. Small insurers have less bargaining power, leading to increasing returns to scale and increased barriers to entry in the health insurance market. In equilibrium, bargaining is likely to result in increased prices for uncovered consumers. There is some evidence in the Medicare Part D market and in the medical device market (Grennan, 2012) that measured discounts are not strongly size-related, but some of this may be due to bargaining over indirect rebates rather than direct discounts that have to be extended to consumers outside the bargaining process.

8. Weak and Inconsistent Incentives Due to Government Regulation: A variety of regulatory mechanisms have been applied to health insurance markets. ${ }^{9}$ In the United States, most regulation of insurers has been in the hands of State agencies, but Federal regulation is important in areas such as Medicare and Medicaid, particularly in the Part D prescription drug insurance program, and in the Patient Protection and Accountable Care Act of 2010 (PPACA) that is currently in the process of implementation. Regulation has had multiple objectives, including control of performance risk of insurers, promotion of social objectives of fairness, elimination of "health inequities" and better health for the public, promotion of affordable health care as a "right" of citizens, limiting the exercise of market power by providers and insurers, monitoring use of public funds spent on health care, limiting the growth of medical expenditures,

\footnotetext{
${ }^{9}$ Selected references are Neudeck and Polezeck (1996), Cutler-Reber (1998), Feldman et al (1998), Glazer (2000), Finklestein (2002), Boccuti and Moon (2003), Pauly and Zeng (2004), Buchmueller (2008), Dhalby (2008), McFadden-Winter-Heiss (2008), Blumberg (2009), Olivella and Vera-Hernandez (2010), and Englehardt (2011).
} 
and blunting the causes of market instability and inefficiency. These objectives can conflict, and can create incentives for insurers, providers, and consumers that are inconsistent with efficient resource allocation. While a number of specific regulatory mechanisms have proven effective for specific purposes, there is no political consensus in the U.S. on what the overall objectives of regulation should be, and only a limited public policy consensus on what combinations of regulatory agencies and tools are the most effective. Most critically, there is very little overall assessment and coordination of regulations and subsidies to identify and repair misaligned incentives, and keep pace with innovations in technology and management of health services. Our earlier paragraph on active moral hazard emphasized the difficulties of achieving compatible incentives when information is asymmetric. A patchwork of inconsistently motivated and poorly coordinated government regulation can have similar consequences, in the same way that poorly designed coverage mandates and limits on underwriting can exacerbate adverse selection.

There are problems of coordination of regulations between States, where insurers operating across State lines or consumers migrating between States can undercut a State's regulations, and problems of coordination of Federal and State regulation. At least some national regulation is required to facilitate interstate operations of insurers and providers without introducing destabilizing "races to the bottom" in which lax regulation in one State allows the market to circumvent stricter regulation desired by the citizens of another State. Clearly in light of the fundamental problems with health insurance markets caused by the factors discussed above, substantial regulation of health insurance markets is essential to achieve efficient and socially acceptable resource allocation. The broad question is how to manage the regulatory system so that it meets its central objectives while minimizing unintended consequences.

Regulatory Remedies for Health Insurance: Table 1 gives a summary of common regulatory mechanisms for health insurance, classified in terms of their primary target: consumers, providers, or insurers. Obviously, some of these regulations must be used in tandem. For example, enrollment mandates on consumers are sensible only with creditable coverage requirements plus guaranteed issue requirements that insurers enroll all persons trying to buy contracts satisfying the creditable coverage minimums.

\section{INSERT TABLE 1 ABOUT HERE}

Consumer-based regulation is intended primarily to blunt adverse selection and to prevent the "free riding” that occurs when the uninsured sick appear in the emergency rooms of hospitals for treatment. Enrollment mandates require consumers to buy creditable coverage insurance contracts even if they would 
not do so voluntarily. Thus, consumers are prevented from bailing out of pooled risk contracts that they consider actuarially unattractive. The effect of enrollment mandates is a cross-subsidy of the less healthy by the more healthy. Enrollment mandates may also nudge consumers to act in their own interest, and overcome faulty perceptions of risk. Enrollment mandates can prevent market unraveling in which the only contracts that can be offered by insurers without a loss are actuarially unfair to all but the highest-risk consumers.

Premium subsidies make insurance contracts more actuarially attractive, and are central to social insurance objectives of providing safety nets for the less fortunate. These subsidies primarily benefit the less healthy, who would otherwise be in risk classifications with high premiums. Means-tested premium subsidies explicitly cross-subsidize the poor, but because the poor are generally less healthy, non-means-tested general premium subsidies are also progressive. The overall progressivity of premium subsidies of course depends on the taxes used to finance them; even a relatively regressive tax earmarked for health insurance premium subsidies will be progressive overall.

Co-payments require that consumer have some skin in the game when they make treatment choices. Reference pricing requires consumers to pay out-of-pocket for treatment costs in excess of the least cost procedure deemed effective for their condition. These regulations reduce active moral hazard by giving consumers an incentive to economize on health purchases, and are often incorporated into “consumer-directed health care” or "Consumer, heal thyself!” initiatives that place more responsibility for treatment choices and costs on the patient. Obviously, the "stick" of high copayments for "over-treatment" can be combined with a "carrot” of refunds for "cost-effective” treatment. However, there is a significant conflict between having consumers see all or most of the true marginal cost of health services, and providing substantial insurance against health risks. There are also substantive problems in determining efficient levels of care that maintain "health capital”, and reduce or delay costly breakdowns later, when patients or providers have private information on treatment efficacy, or when consumers discount or underestimate the probability of future health problems and undervalue preventative care. As many scholars have noted, "moral hazard” is an unfortunately loaded term for a price-service margin where care is needed to handle external and information effects and get the incentives right.

Provider regulation is intended primarily to blunt incentives for inappropriate or unnecessary treatments that increase provider income, and to give consumer and insurer payers more control over and interest in controlling medical costs. Capitation, a fixed fee for treatment of a diagnosed condition, is a common method, but one that may induce inappropriate "up-coding” of diagnoses and risk adjustments, rejection of patients requiring costly treatment, or under-treatment. Outcome-based "accountable care" 
payment may be an effective tool, but risk-adjustments and lags in observing outcomes are challenges to implementation.

Insurer regulation includes tools that are often deployed in markets where the suppliers are concentrated, those where product quality is not easily determined by the buyer, and those where performance risk is an issue. For example, rate-of-return or price (premium) regulation is common in concentrated industries and natural monopolies, and entry controls and capitalization requirements are typical for financial and insurance industries where there is default risk. Franchising is a form of entry regulation that can prevent market unraveling due to cherry-picking by rivals; single-payer health insurance systems are an extreme case of franchising.

Controls on risk classification and screening, guaranteed issue, exclusions for pre-existing conditions, and rescission are necessary if consumers face mandates for coverage, and can also be used to block channels through which insurers trying to position contracts to combat adverse selection may cause markets to unravel. However, these regulations, and limits on underwriting, can also be counter-productive in the absence of consumer mandates, forcing pooling across risk classes that feeds adverse selection. Finally, there are regulations on insurers that limit adverse selection, including regulatory control of contract terms to require creditable coverage and limit cherry picking, premium subsidies, ex ante risk adjustment, ex post experience adjustment, and reinsurance. Effective risk adjustments and reinsurance are very important, and usually require public subsidies, although in some cases they can be achieved through mandated pooling of industry risks.

In this paper, we will focus on the problems of undercoverage and market instability that can occur when insurers can introduce contracts in the market that undercut contracts with more generous benefits by cherry-picking their lowest-risk enrollees who are the least expensive to serve. In the terminology of Akerlof (1970) and Miyazaki (1977), the result may be a "rat race" in which contracts that attract heterogeneous risk pools cannot be sustained and the market fragments into many different contracts, with the more healthy consumers fleeing to contracts with insufficient coverage to attract the less healthy consumers. In the extreme, the market may "unravel from the top", with insurers unable to offer a sustainable contract that only the most healthy will buy, and absent such a contract unable to offer a sustainable contract that the next most healthy will buy, and so on in a race to be bottom in which there is only one stable surviving contract that attracts only the least healthy. In this extreme, "bad" consumers with high health risks drive "good" consumers with low health risks out of the market, a health insurance version of Gresham's Law. For shorthand, we lump all these outcomes under the term "market unraveling". 
Asymmetric information, with consumers knowing more about their health risks than insurers can observe or use, and the resulting adverse selection, can cause market unraveling, but so can regulations that limit competitive underwriting, and consumer misperceptions that underestimate the probability or range of the possible health problems they face. We will argue in the following section that creditable coverage regulation that restricts the health insurance contracts that insurers can offer can be an effective tool to prevent market unraveling, essentially by ensuring that contracts purchased by a pool of consumers with heterogeneous health risks cannot be cannibalized by contracts with less generous coverage that cherry-pick the most profitable customers. In a pool supported by creditable coverage regulation, the least risky cross-subsidize the most risky, a feature that may or may not be judged socially desirable, but all risk classes in the pool may nevertheless be better off than in an unregulated market that is fragmented into contracts with incomplete coverage, induces costly and onerous risk classification, or fails to achieve an equilibrium in which insurance contracts are available.

It is obvious that an enrollment mandate without coverage regulation cannot prevent market fragmentation and undercoverage: competitive insurers could continue to cherry-pick by offering cheap contracts with low expected benefits that only low-risk consumers find attractive. On the other hand, while creditable coverage regulation has more scope and can be more effective in the presence of enrollment mandates, by ruling out non-enrollment or self-insurance as a contract option, it can be effective even in the absence of enrollment mandates. If the lowest risk consumers are substantially risk adverse, then creditable coverage regulation can attract most low-risk consumers, as they will prefer partial insurance to none even if the contract is loaded against them due to pooling with riskier consumers. However, if the lowest-risk consumers are not very risk-adverse, or if they underestimate their own risk or are certain about the losses they will incur, they will be unwilling to tolerate much loading, so that creditable coverage regulation without enrollment mandates or premium subsidies may fail to achieve an equilibrium, or attain an equilibrium with socially unacceptable numbers of uninsured. Of course, premium subsidies can be used to draw low-risk consumers into a pooled contract even if they are not very risk adverse, and are an important regulatory alternative or supplement to enrollment mandates.

\section{SELECTION}

We have noted that selection, the phenomenon in which the enrollees in an insurance contract have risk characteristics different than the population as a whole, can arise from asymmetric information about the costs or benefits to be derived from the contract, from legal restrictions on underwriting, issue, and 
rescission driven by social sentiment, and from consumer misperceptions of risk or of uncertainty. Selection becomes an issue in market operation when it is destabilizing, or when it interferes with efficient resource allocation. Screening, a device used by insurers to refuse contracts to people that on the basis of observable information will have an expected service cost that exceeds the premiums they can be charged, or to set premiums people judge to be actuarially adverse, can be costly to conduct and can lead to large numbers of consumers who are uninsured or underinsured. Selection can be either adverse or advantageous from the perspective of insurers, and in principle can distort resource allocation in either direction, but adverse selection is of more concern. It is useful to begin a discussion of selection by reviewing the classical graphical analysis of Rothschild-Stiglitz (1976). This analysis concentrates on the availability of coverage and generosity of benefits for a single health condition; later, we consider scope of coverage over a distribution of health conditions, which involves many of the same issues.

\section{FIGURE 1 ABOUT HERE}

One consumer risk class: Figure 1 shows the preferences of a single consumer for consumption contingent on two future states of the world, healthy and sick. The consumer's indifference curves reflect her beliefs regarding the probability of these states, and her attitudes toward risk. Specifically, if the consumer is an expected utility maximizer, then an indifference curve is a locus of points $(\mathrm{H}, \mathrm{S})$ where $\mathbf{E U}=$ $\mathrm{pu}(\mathrm{S})+(1-\mathrm{p}) \mathrm{u}(\mathrm{H})$ is constant, with $\mathrm{p}$ the probability of becoming sick, $\mathrm{S}$ and $\mathrm{H}$ the levels of consumption in the sick and healthy states, respectively, and $\mathrm{u}(\cdot)$ a utility function of consumption outcomes. The consumer is risk-adverse if $\mathrm{u}(\cdot)$ is a concave function and the indifference curves are strictly convex; risk-neutral if $\mathrm{u}(\cdot)$ is a linear function and the indifference curves are linear. Hereafter, we assume that all consumers are strictly risk adverse. The slope of an indifference curve is $\mathrm{dS} / \mathrm{dH} \equiv-(\partial \mathbf{E U} / \partial \mathrm{H}) /(\partial \mathbf{E U} / \partial \mathrm{S}=$ $-(1-\mathrm{p}) \mathrm{u}^{\prime}(\mathrm{H}) / \mathrm{pu}^{\prime}(\mathrm{S})$; on the $45^{\circ}$ diagonal where $\mathrm{S}=\mathrm{H}$, this slope is $-(1-\mathrm{p}) / \mathrm{p}$. The diagram shows the indifference curves through $\mathrm{E}$ and through two other points, $\mathrm{A}$ and $\mathrm{B}$, defined below. For this discussion, we ignore the issue of moral hazard, where $\mathrm{p}$ becomes a function of (unobserved) effort by the consumer to avoid becoming sick or to mitigate loss. The point $\mathrm{E}=\left(\mathrm{H}_{0}, \mathrm{~S}_{0}\right)$ gives consumption in the case of no insurance, with $\mathrm{L}=\mathrm{H}_{0}-\mathrm{S}_{0}$ equal to the lost consumption due to medical expenses if sick.

Consider an insurance contract with premium $\pi$ that pays a share $\theta$ of the loss if the consumer becomes sick, the benefit $\theta \mathrm{L}$. The consumer's copayment if sick is $(1-\theta) \mathrm{L}$. Partial or full insurance has $0<\theta \leq 1$, but the notation can also encompass over-insurance, a bet that the consumer will become sick $(\theta>1)$; and counter-insurance, a bet that the consumer will stay healthy $(\theta<0)$. We will assume in this paper that legal health insurance contracts must satisfy $0<\theta \leq 1$; i.e., consumers are not allowed to bet on health via 
over-insurance or counter-insurance. Contracts for a fixed $\theta$ and various premiums $\pi$ lie along a $45^{\circ}$ line aa that is parallel to the diagonal and goes through the point $A^{*}=\left(\mathrm{H}_{0}, \mathrm{H}_{0}-(1-\theta) \mathrm{L}\right)$. The point $\mathrm{A}$ on this line where the premium equals the expected benefit, $\pi=\mathrm{p} \theta \mathrm{L}$, is the actuarially fair contract. Contracts on the line aa southwest of this point are actuarially adverse for the consumer and profitable for the insurer, while those northeast of this point are actuarially advantageous for the consumer and unprofitable for the insurer. If insurers are competitive and the administrative overhead of providing insurance is negligible, then competition between insurers offering contracts in the aa line drives their premiums to the single price at the point A.

Consider the line $\underline{b}$ through the points $E$ and $A$. The slope of this line is $-(1-p) / p$, given by the ratio of the net increase in income from $\mathrm{E}$ to $\mathrm{A}$ if consumer becomes sick, the benefit less the premium, or (1-p) $\theta \mathrm{L}$, to the net increase in income if the consumer stays healthy, the negative of the premium, or $-\mathrm{p} \theta \mathrm{L}$. This slope depends only on the probability of becoming sick, and holds for any $\theta$, so that any insurance contract on the line $\underline{b b}$ is actuarially fair. A risk adverse consumer given the option of any actuarially fair insurance contract, that is to say any point on the budget line $\underline{b b}$, will choose the full insurance contract on the $45^{\circ}$ diagonal, $\mathrm{B}=\left(\mathrm{H}^{\prime}, \mathrm{S}^{\prime}\right)$ where $\mathrm{H}^{\prime}=\mathrm{S}^{\prime}=\mathrm{H}_{0}-\mathrm{pL}$ and the slope of the budget line equals the slope of the indifference curve. A strongly risk-adverse consumer will have an indifference curve that is nearly L-shaped, while a nearly risk-neutral one will have an indifference curve that is almost flat, but if both have the same p, then they both have the same slope at the $45^{\circ}$ diagonal. Any insurance contract northeast of the consumer's indifference curve through E, actuarially fair or not, will be preferred to no insurance. In the case of a nearly risk-neutral consumer, this will include only contracts close to actuarially fair, while for a strongly risk-adverse one, there will be many contracts better than the no insurance point E. In the latter case, the consumer is willing to tolerate a substantial adverse load to gain the benefit of reduced risk.

If (1) all consumers have the same probability p of being sick, or these probabilities vary but consumers are unable to use private information to estimate them more accurately than insurers can do based on public information, (2) underwriting can freely use estimates of p to establish actuarially fair premiums for each consumer, (3) moral hazard does not introduce a dependence between level of insurance and probability of becoming sick, and (4) insurers are competitive and administrative overhead is negligible, then an efficient market equilibrium is achievable at which each consumer buys actuarially fair full insurance. ${ }^{4}$

\footnotetext{
${ }^{4}$ If all these conditions hold except that there is administrative cost of providing insurance that is proportional to the coverage rate $\theta$, then the locus of breakeven contracts will be less steep than the line bb, and given a choice among all break-even contracts, the consumer will choose less than full insurance, with the degree of risk aversion determining how much less. Alternately the health insurance business may be imperfectly competitive, with fixed costs of entry, the case that is a focus of McFadden-Noton-Olivella (2012). One possible market equilibrium in this full information case is a monopolist selling full insurance at a profitable premium that just low enough to forestall entry.
} 


\section{FIGURE 2 ABOUT HERE}

Two consumer risk classes: Now suppose there are two classes of consumers, robust and frail. A robust consumer has a probability $\mathrm{p}^{\prime \prime}$ of becoming sick that is lower than the probability $\mathrm{p}^{\prime}$ of a frail consumer becoming sick. Each consumer knows her own probability. Suppose that insurers cannot distinguish robust and frail consumers, or are required to sell contracts at the same premium to consumers from either class even if they could be distinguished. Figure 2 depicts these consumers, where we assume that they have exactly the same consumption outcome $\mathrm{E}$ if they have no insurance. The case depicted in the figure has a common utility function $\mathrm{u}(\cdot)$ for both risk classes, so that aside from the risk of becoming sick, tastes are the same. In this case, at any point on or below the $45^{\circ}$ diagonal, the indifference curve of a robust consumer is steeper than the indifference curve of a frail consumer. We concentrate on this case, but also include analysis of the case in which robust consumers are much more risk adverse than frail consumers, so that at points sufficiently below the $45^{\circ}$ diagonal, the indifference curves of robust consumers are less steep. The actuarially fair contracts for the two classes separately are given by the line $\underline{b b}$ through E with slope $-\left(1-p^{\prime}\right) / p^{\prime}$ for frail consumers and the line cc with the steeper slope $-\left(1-\mathrm{p}^{\prime \prime}\right) / \mathrm{p}^{\prime \prime}$ for robust consumers. Let $\gamma$ denote the share of the consumers who are frail. Then, the probability that a consumer from the pool of all robust and frail consumers will become sick is $\mathrm{p}^{*}=\gamma \mathrm{p}^{\prime}+(1-\gamma) \mathrm{p}^{\prime \prime}$. The line dd through point E with slope -(1-p*)/p* contains the contracts that break even when both frail and risky consumers buy them. When the share of frail consumers is large, the line $\underline{\mathrm{dd}}$ will be close to the line $\underline{\mathrm{cc}}$, and when the share of frail consumers is small, it will be close to the line $\underline{b b}$.

Consider again contracts in the line aa that for various premiums pay the benefit $\theta \mathrm{L}$ if a consumer becomes sick. If only robust consumers buy this contract, it will break even at a premium that gives the point F. If only frail consumers buy it, then it will break even at the point A. Finally, if the pool of both frail and robust consumers buy it, the breakeven contract is D.

Cherry-picking blocks and pooled contract failure: A consumer will choose from available options the contract that maximizes utility, with no insurance (self-insurance) always an available alternative. The menu of contracts available in the market, each characterized by a coverage level $\theta$ and a premium $\pi$, will be determined by competition between insurers. A competitive equilibrium is defined by a menu of contracts such that no insurer could by introducing, withdrawing, or changing the premium on a contract increase its profit. This profit calculation is made under the assumption that consumers will respond to the actions of an insurer by re-maximizing their utilities, and in particular will buy from the firm offering the lowest premium for a specified contract, and the Nash assumption that rivals will not respond to the insurer's 
actions by changing their own offers. When there are no regulations restricting the contracts that can be offered, then in competition between many small insurers, each with eventually non-decreasing average costs of serving consumers with given profiles of risk characteristics, every contract in the market menu must break even, as money-losing contracts will be withdrawn, and profitable contracts will have their premiums bid down by competition until excess profits are exhausted. Further, no non-offered contract could yield a positive profit, given the market menu in place, since it would otherwise be introduced by some firm.

\section{FIGURE 3 ABOUT HERE}

With this background, we can now give the Rothschild-Stiglitz argument that no contract that attracts a pool of both frail and robust consumers is viable in a competitive market menu. The reason will be that any pooled contract is either itself inferior to a second pooled contract for both risk classes, or else can be undercut by rivals introducing a new contract that cherry-picks away its robust consumers and leaves the frail ones behind. In the second alternative, the resulting adverse selection would increase the expected benefit payout for those remaining in the pooled contract so that it would no longer break even. Consider the contract $\mathrm{D}$ on the line $\underline{\mathrm{dd}}$ in Figure 3, and suppose that it is in a pool with both frail and robust purchasers, so that it is breaking even. (This is depicted in the case that the share of frail consumers buying this contract is the same as their population share $\gamma$, but the following argument works for any share $0<\gamma<$ 1 that involves pooling consumers from both risk classes.) The slope of the indifference curve of frail consumers through $\mathrm{D}$ must be less steep than the slope of the pooled break even line $\underline{\mathrm{dd}}$, as their indifference curve below the diagonal can be no steeper than the line bb which is less steep than the line $\underline{\mathrm{dd}}$. In general, the indifference curve of robust consumers through $\mathrm{D}$ could either be at least as steep as the line dd, or less steep than $\underline{\mathrm{dd}}$ (not shown). In the latter case, rivals could introduce a contract with larger $\theta$ just below the line $\underline{\mathrm{dd}}$ and above the indifference curves of both frail and robust consumers through $\mathrm{D}$. This would be superior for both frail and robust consumers and earn positive profits if they move to it, blocking D. Therefore, the only possibility for $\mathrm{D}$ to be viable is that the indifference curve of robust consumers through D is at least as steep as $\underline{\mathrm{dd}}$, as depicted. But if this is true, then the contract G, shown in the figure, that lies above the indifference curve of robust consumers through $\mathrm{D}$, and below the indifference curve of frail consumers through D, could be introduced. This contract would cherry-pick the robust consumers away from the contract $D$. The contract $G$ would be profitable in the presence of $D$, as it attracts only robust consumers and is southwest of the breakeven line ç for robust consumers alone. On the other hand, $\mathrm{D}$ would now lose money, as it retains only frail consumers and is northeast of the breakeven line bb for 
frail consumers alone. Consequently, a competitive market equilibrium cannot include a pooled contract like D. ${ }^{6}$

\section{FIGURE 4 ABOUT HERE}

Rothschild and Stiglitz go on to show that there may be a stable competitive market equilibrium that is separating, with frail consumers buying an actuarially fair full insurance contract B and robust consumers buying actuarially fair partial insurance at a contract $\mathrm{H}$ with coverage so low that is not more attractive to frail consumers than B. This situation is depicted in Figure 4, with $\mathrm{H}$ located at the intersection of the breakeven line cc for robust consumers alone and the indifference of frail consumers through $\mathrm{B}$. In this figure, the breakeven line dd for pooled contracts does not intersect the robust consumers' indifference curve through $\mathrm{H}$. Then, there is no contract $\mathrm{G}$ just below $\underline{\mathrm{dd}}$ and above the robust consumer indifference curve that could attract both frail and robust consumers and be profitable. Conversely, if the robust consumers' upper contour set of points better than $\mathrm{H}$ does intersect $\mathrm{dd}$, the potential separating equilibrium would be blocked by a pooled contract $\mathrm{G}$ (not shown) on $\underline{\mathrm{dd}}$ and above the robust indifference curve through $\mathrm{H}$. Now, we already know that a pooled contract can itself always be blocked, so that in the last case, no stable competitive market equilibrium exists. Observe that when the share of frail consumers becomes small, the breakeven line $\underline{\mathrm{dd}}$ for pooled contracts approaches the breakeven line $\underline{\mathrm{cC}}$ for robust consumers alone. Then for sufficiently small $\gamma$ one will be in the case where no stable competitive market equilibrium exists. The market in this case can be said to unravel from the top, with no sustainable contract targeted to the robust consumers.

There has been considerable discussion of non-existence of competitive equilibrium and its consequences in the Rothchild-Stiglitz setting. One possibility is that the market will settle at some refined equilibrium in which insurers offer menus of contracts that may contain cross-subsidized "loss leaders" that shelter other offerings and make their menus profitable overall, and have sufficient foresight to forego introducing contracts whose profitability requires the presence of incompatible contracts that cannot co-exist, thus allowing some pooling and separating contracts to survive. ${ }^{10}$ Another is that the market will

\footnotetext{
${ }^{6}$ In the case of a contract $\mathrm{D}$ on $\underline{\mathrm{dd}}$ that provides full or over-insurance, $\theta \geq 1$, the slope of the robust consumer indifference curve at $\mathrm{D}$ must be steeper than the slope of dd. If the indifference curve of frail consumers through $\mathrm{D}$ is steeper than $\mathrm{dd}$, then $\mathrm{D}$ will be blocked by a pooled contract just below $\mathrm{dd}$ with lower $\theta$, and if the indifference curve of frail consumers is at no steeper than dd, then there is a cherry picking contract $\mathrm{G}$ with lower $\theta$ that will profitably attract only robust consumers and will block $\mathrm{D}$ because it will be left with only frail consumers and will become unprofitable.

${ }^{10}$ Wilson $(1977,1979,1980)$ shows that some menus that are not viable under Nash competition may be so in such expectational equilibria, with firms making conjectures on the responses of rivals. Other game-theoretic alternatives
} 
"churn” continuously, with entry and exit of contracts, and unsatisfied demand. It appears that in the market for individual health insurance in the U.S., consumers often feel that they cannot obtain actuarially fair insurance with close to full coverage. Some of this may be misperception, but market unraveling also seems to be going on, either a "rat race" in which the only contracts available to robust consumers that are actuarially fair have very limited coverage, or an unstable market in which the "bad" frail consumers drive out the "good" robust consumers. If what we are observing in the U.S. is a "rat race", achieved either with basic competition or with refinements, then these equilibria apparently do not substantially reduce the incentives for insurers to screen on the basis of observables and use rejections to improve the risk characteristics of its enrollees in any contract, and do not appear to be efficient or equitable enough to satisfy social sentiment for health outcomes that are comparable to national health systems in other developed countries.

Many Risk Classes: The Rothchild-Stiglitz analysis with two consumer risk classes has a straightforward extension to many risk classes. The argument for non-viability of pooled contracts requires only comparisons of two risk classes, and remains the same even if there are many risk classes. More risk classes make it more difficult for a stable competitive separating market equilibrium to exist. Riley (1979, Theorem 3 and discussion) shows that when there is a continuum of consumers just above a given risk class, a stable separating market equilibrium cannot exist. The analysis of Hendren (2011) shows however that there may be decentralized incentive-compatible designs that will lead to stable equilibria for some consumer segments.

\section{CREDITABLE COVERAGE REGULATION}

We will examine closely creditable or minimum coverage requirements for offered contracts in markets with competitive insurers, and the effect of this form of regulation on adverse selection. The usual form of minimum coverage requirements is that they mandate standardized contracts or require that contracts offered in the market encompass specified lists of conditions and procedures, providers, and covered persons. For example, Medicare Part D prescription drug coverage in the United States is offered by

to competitive Nash behavior of suppliers have been considered by Miyazaki (1977), Crocker-Snow (1985ab), Cho-Kreps (1987), Hellwig (1987), Rose (1993), Gale (1992, 1996), Allard et al (1997), Lopez-Cunat (2000), Villeneuve (2000), Dionne et al (2001), Blouin (2003), Hendel (2005), and Chade-Schlee (2011). Hendren (2011) uses the tools of mechanism design to establish a critical condition for the existence of any incentive-compatible design for a decentralized health insurance market, and gives evidence that this condition may not be satisfied. 
competitive insurers with a standard contract, market-determined publically-subsidized premiums, and creditable coverage requirements that offered contracts be at least as generous as the standard contract, and meet specific conditions on formularies and copayment limits. It is important to note that effective creditable coverage regulations require lower limits on the generosity of benefits as well as lower limits on the conditions or procedures that must be covered. Table 2 describes State condition and procedure coverage mandates for employer-provided or publically subsidized general health insurance in the United States. In addition, States have mandates on the types of providers that must be covered, and on household or family members who must be covered. It is apparent from this table that while coverage mandates are common, there is no uniform standard for what mandates are justified in terms of health outcomes, or what mandate designs are helpful in stabilizing health insurance markets. These mandates increase the cost of health insurance, and result in cross-subsidies from the relatively healthy to people with specific health conditions. They also increase the cost of employer-provided insurance, leading business groups to strongly oppose mandates; see Bunce and Weiske (2010), Keating (2012). Coverage mandates can induce adverse selection, by making contracts more actuarially adverse for the healthy, but can also restrict the ability of insurers to tailor contracts to cherry-pick lower-risk consumer.

\section{TABLE 2 ABOUT HERE}

In tandem with "guaranteed issue” and "no rescission" requirements on insurers, particularly with premium subsidies and risk adjustments, creditable coverage regulation can be an effective tool to control adverse selection and prevent unraveling. On the other hand, mandates enacted at the behest of specific provider and interest groups without considering their overall consequences may exacerbate adverse selection. Thus, for creditable coverage regulation to be effective for health outcomes and market stabilization, it needs to be implemented with careful attention to the health value of specific mandates and the consequences for market operation. We argue in this paper that coverage mandates are a powerful tool for stabilizing health insurance markets and reducing inefficiencies, but note that to help rather than hurt, coverage mandates have to be carefully designed.

Enrollment mandates can be used to improve the effectiveness of creditable coverage regulation and reduce the need for premium subsidies. In particular, if there are not enrollment mandates, then in general there will be a delicate trade-off between the scope of mandated coverage and voluntary enrollment of healthy people that lower the average benefit payout. On the other hand, enrollment mandates are ineffective without some level of minimum coverage regulation combined with sufficient penalties to prevent consumers from ignoring the enrollment mandates. Overall, enrollment mandates are an 
important tool in promoting health insurance market efficiency, but it would also be possible to achieve stability and acceptable efficiency in health insurance exchanges through use of standardized contracts and creditable coverage restrictions, premium subsidies, and risk adjustment if enrollment mandates were removed as a policy tool.

Creditable coverage, premium support, and enrollment mandates: Consider regulatory measures to combat the failures of health insurance markets in the presence of adverse selection, the non-viability of pooled contracts as in Figure 3, and the instability or lack of coverage for low-risk consumers as in Figure 4. The challenge is to obtain high enrollment and high rates of coverage by preventing pooled contracts from being blocked. Creditable coverage regulation approaches this by restricting the coverage of contracts that are allowed in the market. In its simplest form, this regulation could specify a single fixed level of coverage $\theta$. Insurers would compete on premiums, but would not be able to introduce contracts with coverage variations that could cherry pick away robust consumers. For example, consider the contract D in Figure 3, and creditable coverage regulation requiring that any offered contract lie in the line aa offering the same coverage as $\mathrm{D}$ at various premiums that will be market determined. If $\mathrm{D}$ is above the indifference curve of robust consumers through the no insurance point E, as shown, then this "all or nothing” contract will attract both risk classes, in which case its location on the dd line will correspond to the competitively determined break even premium. Except for the corner case where the indifference curve of robust consumers at $\mathrm{E}$ is steeper than dd, so they will buy no contract on dd with $0<\theta$, there will always be some pooled contract $\mathrm{D}$, protected by creditable coverage regulation from cherry picking, that is better for robust consumers than $\mathrm{E}$, and better for frail consumers than A. If the robust consumer indifference curve through E intersects the $45^{\circ}$ diagonal to the southwest of the contract $\mathrm{L}$ at the intersection of dd with the $45^{\circ}$ diagonal, then $\mathrm{L}$ is a Pareto optimal full insurance contract for both risk classes. While robust consumers would prefer less insurance than $\mathrm{L}$ along the pooling line $\mathrm{dd}$, and frail consumers would prefer more insurance, the creditable coverage restriction of legal contracts to lie on the $45^{\circ}$ diagonal prevents entry of a blocking cherry-picking contract. The second possibility is that the indifference curve of robust consumers through $\mathrm{E}$ lies above $\mathrm{L}$, and the range of viable pooled contracts protected by creditable coverage regulation lie in an interval on dd that is strictly between $\mathrm{E}$ and L. Over this interval, larger $\theta$ is always better for frail consumers, while there will be an optimal $\theta$ for robust consumers. If the creditable contract $\mathrm{D}$ is established to the southeast of this optimum, then both consumer classes would benefit from increased coverage. If $\mathrm{D}$ is located on dd northwest of this optimum, the interests of frail and robust consumers are opposed, and there will be an interval of contracts that are all second-best Pareto optimal, with increasing $\theta$ better for frail and worse for robust consumers. In this range, enrollment does not 
depend on $\theta$, a feature that reappears below when we discuss creditable scope regulation. In the final alternative, not shown, where robust consumers prefer $\mathrm{E}$ to $\mathrm{D}$, the market collapses to an extreme version of a separating equilibrium in which frail consumers obtain creditable insurance at the point $\mathrm{A}$ at the intersection of the lines $\underline{a a}$ and $\underline{b b}$, and robust consumers choose the no insurance point $\mathrm{E}$. The obvious critical condition for creditable coverage regulation to sustain a pooled market equilibrium is then that the robust consumers' indifference curve at $E$ be less steep than the slope of the line $\underline{\mathrm{dd}}$. This condition will be met if robust consumers are sufficiently risk adverse, but the existence of a sustainable creditable pooled equilibrium contract does not guarantee that this contract would provide a socially acceptable level of coverage, or that a pooled contract that is socially acceptable would attract robust consumers. Obviously, an enrollment mandate excludes the last possibility and makes any D on the $\underline{\mathrm{dd}}$ line stable. We show below that the same outcome can be obtained using premium subsidies.

More elaborate creditable coverage schemes could (1) set minimum rather than fixed coverage requirements corresponding to $\mathrm{D}$, and allow insurers to offer alternatives with greater coverage than $\mathrm{D}$, (2) establish a basic coverage requirement like $\mathrm{D}$, and allow insurers to offer supplementary policies to consumers who have purchased D, or (3) require insurers to guarantee issue for a specified menu of contracts, with or without restrictions on cross-subsidization. Consider the first of these schemes in the case that $\mathrm{D}$ is preferred to no insurance by robust consumers. If robust consumers do not prefer more coverage than $\mathrm{D}$ along the dd budget, then no pooled contract that exceeds the creditable minimum can attract them. Then, $\mathrm{D}$ is a stable competitive market equilibrium subject to minimum creditable coverage regulation. On the other hand, if robust consumer preferences are maximized subject to $\underline{\mathrm{dd}}$ at a contract with a larger $\theta$ than $\mathrm{D}$, this will block the contract $\mathrm{D}$ and can in turn be blocked by a cherry picking contract with less coverage that still meets the creditable minimum but attracts only the robust. Consequently, creditable minimum coverage regulation can sustain a stable competitive equilibrium only if robust consumers do not prefer more insurance than the minimum among contracts on the dd line, and if their upper contour set through $\mathrm{E}$ includes the creditable minimum.

Suppose that the basic contract $\mathrm{D}$ is a sustainable as a creditable market equilibrium, and now suppose insurers are allowed to offer supplementary (secondary) contracts to consumers who purchase D. Suppose further than these supplements are not controlled by creditable contract restrictions. This situation is like that in Figure 3, writ small, with $\mathrm{D}$ replacing $\mathrm{E}$ as the starting point. There can be no supplemental insurance contract that attracts the pool of both frail and robust customers. Such a contract would lie in $\underline{\mathrm{dd}}$, and could be blocked by a cherry picking supplemental contract located between the indifference curves of the two risk classes through the pooled basic contract and pooled supplement. However there is a separating equilibrium for supplemental insurance when robust consumers prefer no contract on the line dd 
to the northwest of the basic contract $\mathrm{D}$, as depicted in the detail given in Figure 5. In this case the frail consumers end up with a supplement that gives them full insurance at $\mathrm{K}$, and robust consumers end up at $\mathrm{J}$ with a partial supplement that does not attract frail consumers away from K. The assumption that the indifference curve of robust consumers is tangent to $\underline{\mathrm{dd}}$ at $\mathrm{D}$ implies that the indifference curve of these consumers through $\mathrm{J}$ does not intersect $\mathrm{dd}$. Then, the points $\mathrm{K}$ and $\mathrm{J}$ define a stable separating equilibrium in the supplementary insurance market at which frail consumers are worse off than at $L$ but better off than at $\mathrm{D}$, and robust consumers are better off than at D. In this case it is unnecessary to stabilize the supplementary insurance market with creditable restrictions that prevent blocking. However, with more risk classes, creditable coverage regulation that specifies fixed basic coverage, fixed secondary coverage, fixed tertiary coverage, and so forth, with voluntary enrollment and guaranteed issue at each level, may be necessary for supplementary market stability.

\section{FIGURE 5 ABOUT HERE}

A third creditable coverage scheme requires that insurers offer a specified menu of contracts, with guaranteed issue for each, with restrictions on cross-subsidization. This could accomplish the same thing as the supplemental insurance market just described, with insurers required to offer a full coverage contract in the $45^{\circ}$ diagonal and a second contract in the $45^{\circ}$ line through $\mathrm{L}$, with a ceiling on premiums for full insurance that forces insurers to offer K. Note that a regulated monopoly insurer (e.g., a single payer) could achieve any resource allocation attainable through creditable coverage regulation, with the possibility that the "all or nothing" choices available to consumers in the offered menu will capture all consumer surplus and achieve second-best Pareto optimality subject to the asymmetric information in the market.

Thus far, we have discussed creditable coverage regulation with minimal consideration of two other regulatory tools to combat adverse selection, enrollment mandates and premium support. Consider enrollment mandates. These require that all consumers buy insurance (or, perhaps, post a bond, demonstrate that they have the financial resources to self-insure, or pay a penalty earmarked for treatment of the uninsured). Clearly, meaningful mandates require that the insurance purchases be creditable, and require guaranteed issue. Mandates make the problem of finding stable creditable market equilibrium with pooled contracts easier, and expand the set of contracts that are sustainable, as they effectively eliminate the no insurance alternative $\mathrm{E}$ for robust consumers and the requirement that the creditable contract be better for robust consumers than E. However, as the preceding paragraphs showed, mandated enrollment is not a prerequisite for market stability, particularly when premium subsidies are available as a policy tool. 


\section{FIGURE 6 ABOUT HERE}

Premium subsidies from government funds can be accomplished by providing vouchers to consumers that can be applied to the purchase of health insurance, or by subsidizing insurers. The second channel can be made incentive-compatible by having insurers bid the premium they seek to offer a specified creditable contract, establish a subsidy that is a specified share of a national average premium bid, and finally require each insurer's premium to equal its bid less the subsidy; this is the scheme used in the Medicare Part D prescription drug market. In Figure 6, a premium subsidy will move the break even point D for a pooled contract to the northeast along aa. If the subsidy is sufficient to move the pooled contract to point $\mathrm{F}$ on the robust consumer break even line cc, there is no longer any possibility of this contract being blocked by a contract with less coverage that cherry picks the robust consumers. The contract F shows a case where there are pooled contracts that offer more coverage, and with a premium subsided to the cc line are preferred by both frail and robust consumers. In particular, the contract $\mathrm{C}$, with full insurance for both frail and robust, is attainable with sufficiently large premium subsidies. No enrollment mandates are required, and creditable coverage regulation is needed only to assure that consumers are at C. Subsidies can be combined with active creditable coverage regulation to assure that a break even subsidized pooled contract in the line aa will attract robust consumers, and provide the basis for a stable pooled market equilibrium. This reduces the public subsidy required relative to the one required to support C. If enrollment mandates are added, it may be possible to reduce further the premium subsidy. A complete analysis of premium subsidies must consider the source of tax revenue to finance them, its deadweight cost, and the overall progressivity of a tax program earmarked for premium subsidies.

Creditable Coverage Regulation with Many Risk Classes: The sustainability of basic creditable coverage regulation that fixes the contract coverage is essentially unchanged if there are many consumer risk classes. Consider again Figure 3, and now assume that the lines aa and cc are breakeven for the upper and lower extremes of risk, but there are now consumers in intermediate risk classes. Assume that $\mathrm{p}^{*}$ is the average risk for the grand pool of all consumers, and dd is the break even line for this grand pool. Then, all consumers at least as risky as $\mathrm{p}^{*}$ will choose $\mathrm{L}$ if it is available in preference to any other contract on or below dd and the $45^{\circ}$ diagonal, and will choose D over E. Consumers only slightly less risky than $\mathrm{p}^{*}$ will prefer more insurance than $\mathrm{D}$ at the price $\mathrm{p}^{*}$, while consumers that are near $\mathrm{p}$ " in risk will, in the case shown in Figure 3, prefer less insurance than D. So long as the consumers in the p" risk class prefer D to E, and intermediate risk classes do as well, D will remain a stable competitive pooled contract when only this coverage level is allowed. However, it will very difficult to achieve a stable market for secondary 
insurance among the purchasers of $\mathrm{D}$, for the same reasons that separating equilibria are difficult to achieve in the original Rothschild-Stiglitz setup when there are many risk classes, as demonstrated by Riley.

Creditable Coverage Scope Regulation: Thus far, we have analyzed creditable coverage regulation when there is a single health problem, and the only issue is the share of the cost of treatment paid as benefits by the insurer. In practice, health insurance contracts can restrict coverage to a specified list of conditions and treatments, as in Table 2, with different benefit formulas for each. For example, in the Medicare Part D prescription drug insurance market, insurers are allowed to specify the formularies they provide, subject to limitations on the number of drugs available for each therapeutic condition, and are allowed to place drugs on different copayment tiers, subject to a requirement that on average they meet a standard criterion for benefit generosity. In the general private health insurance market, plans may differ on coverage and restrictions for a variety of conditions and needs, from contraceptives to preventative and maintenance therapies to surgical and hospital charges.

A tractable model of coverage scope starts with the assumption that each consumer faces a continuum of health conditions indexed by the points in the unit interval. Suppose that for selected $\theta$, insurance contracts with premiums $\pi(\theta)$ are available that covers all losses from conditions in $[0, \theta]$, and no losses from the conditions in $(\theta, 1]$. Obviously, $\theta=0$ with $\mathrm{p}(0)=0$ corresponds to no insurance, and increasing $\theta$ corresponds to increasing scope of coverage. Figure 7 illustrates a locus, labeled ABC, of insurance contracts that might be offered in the market, each characterized by its scope and premium. Assume that each consumer chooses a contract $\theta$ to maximize a certainty-equivalent net expected payoff $\theta(\mu+\eta)-\pi$ over the available $(\theta, \pi)$ scope-premium pairs, where $\theta(\mu+\eta)$ is the certainty equivalent value of benefits from insurance against losses from the conditions $[0, \theta], \mu$ equals the consumer's expected benefit from all conditions if fully insured, and $\eta>0$ equals the certainty equivalent value of eliminating all risk. ${ }^{11}$ This payoff function increases to the southeast in Figure 7, with the line cc with slope $\mu+\eta$ denoting the linear indifference curve through the best point B for this consumer, with coverage scope $\theta^{*}$. Then for all $\theta^{\prime \prime}>$ $\theta^{*}, \theta^{*}(\mu+\eta)-p\left(\theta^{*}\right) \geq \theta^{\prime \prime}(\mu+\eta)-\pi\left(\theta^{\prime \prime}\right)$ and hence $\mu+\eta \leq \partial_{+} \pi(\theta) \equiv \inf _{\theta^{\prime \prime}>\theta}\left[\pi\left(\theta^{\prime \prime}\right)-\pi(\theta)\right] /\left[\theta^{\prime \prime}-\theta\right]$ where "inf” is over all the contracts available in the stated range. Similarly, $\mu+\eta \geq \partial \pi(\theta) \equiv \sup _{\theta^{\prime}<\theta}\left[\pi(\theta)-\pi\left(\theta^{\prime}\right)\right] /\left[\theta-\theta^{\prime}\right]$.

\footnotetext{
${ }^{11}$ This specification comes from consumers who are expected utility maximizers with a constant absolute risk aversion (CARA) utility function $\mathrm{u}=[1-\exp (-\alpha(\mathrm{c}-\pi(\theta)-\mathrm{L}))] / \alpha$, where $\mathrm{c}-\pi(\theta)-\mathrm{L}$ is consumption after paying premium $\pi(\theta)$ and a out-of-pocket loss $L$ from uninsured health care costs from conditions $(\theta, 1], \alpha>0$ is a coefficient of risk aversion, and health care losses are described by a Weiner process with drift; i.e., the loss $L$ from conditions $(\theta, 1]$ has a normal distribution $L \sim N\left((1-\theta) \mu,(1-\theta) \sigma^{2}\right)$, with $\mu>0$ and $\sigma^{2}>0$. The expectation of this utility function, obtained from the moment generating function for the normal, is $\left.\mathbf{E u}=\left[1-\exp \left(-\alpha(\mathrm{c}-\pi(\theta)-(1-\theta) \mu)-(1-\theta) \alpha \sigma^{2} / 2\right)\right)\right] / \alpha$, so that expected utility is maximized when $\theta\left(\mu+\alpha \sigma^{2} / 2\right)-\pi(\theta)$ is maximized; see Sharpe (1964), Mailath, and Noldeke (2008). The expected net benefit from insurance $\theta$ is $\theta \mu-\pi(\theta)$, and the certainty equivalent value of risk reduction is $\theta \eta=\theta \alpha \sigma^{2} / 2$.
} 
Then for every contract $\theta$ offered and chosen by some consumers, a price schedule $\pi(\theta)$ consistent with consumer optimization satisfies $0<\left[\pi(\theta)-\pi\left(\theta^{\prime}\right)\right] /\left[\theta-\theta^{\prime}\right] \leq\left[\pi\left(\theta^{\prime \prime}\right)-\pi(\theta)\right] /\left[\theta^{\prime \prime}-\theta\right]$ for $\theta^{\prime}<\theta<\theta^{\prime \prime}$ Then $\pi(\theta)$ must be increasing and convex on the domain of available contracts. Further, if $\partial \pi(\theta)<\partial_{+} \pi(\theta)$, then $\theta$ is the unique optimal choice for any consumer that has $\mu \in\left(\partial \pi(\theta)-\eta, \partial_{+} \pi(\theta)-\eta\right)$. Thus, in Figure 7 , where $\mathrm{B}$ is a kink in the locus of available contracts, all the consumers with $\mu$ in the interval $\left(\partial-\pi\left(\theta^{*}\right)-\eta, \partial_{+} \pi\left(\theta^{*}\right)\right.$ - ๆ) will choose $\theta^{*}$.

\section{FIGURE 7 ABOUT HERE}

Assume that $\mu$ is private information to the consumer, and is heterogeneous and continuously distributed in the population with a support $\left[\mu_{0}, \mu_{1}\right]$ satisfying $0<\mu_{0}<\mu_{1}<\infty$ and a positive continuous density on the interior of this support; this private information will then be a potential source of adverse selection. This model is a highly stylized characterization of conditions and losses, and the one-dimensional characterization of scope and risk heterogeneity is quite special, but it captures the essential feature of scope - more limited coverage increases exposure to risk. The expected risk of a pool of consumers with $\mu \in[a, b] \subseteq\left[\mu_{0}, \mu_{1}\right]$ will be denoted $\mathrm{M}(a, b)=\mathbf{E}\{\mu \mid a \leq \mu \leq b\}$; then $\mathrm{M}(a, a)=a$, and for a constant $C>0$ that is independent of $a$ and $b, a+1 / 2 C^{-1}(b-a) \leq \mathrm{M}(a, b) \leq b-1 / 2 C(b-a){ }^{12}$

A contract $\theta$ breaks even if the premium equals the expected benefit payout to the consumers who choose this contract, $\mathrm{p}(\theta)=\theta \cdot \mathrm{M}(a, b)$, where $a=\partial_{-} \pi(\theta)-\eta$ and $b=\partial_{+} \pi(\theta)-\eta{ }^{13}$ Then the premium on a breakeven contract must satisfy $\partial \pi(\theta)-\eta \leq \pi(\theta) / \theta \leq \partial_{+} \pi(\theta)-\eta$, with the inequalities strict when $\partial-\pi(\theta)<$ $\partial_{+} \pi(\theta)$. Competitive market equilibrium is defined by a compact set of offered contracts $\theta$, with premiums $\pi(\theta)$ and consumer choices across contracts at these premiums such that all offered and chosen contracts break even, and no other contract if introduced would be profitable while the previously offered contracts all remain in the market.

\section{FIGURE 8 ABOUT HERE}

In the absence of creditable scope regulation, this paragraph shows that market equilibrium cannot exist: First suppose, as in Figure 8, that a candidate equilibrium exists in which a contract B is chosen by a

${ }^{12}$ If $f(\mu)$ is the density of $\mu$, then $\mathrm{M}(a, b)=\int_{a}^{b} \mu f(\mu) d \mu / \int_{a}^{b} f(\mu) d \mu$. Since $f$ is positive and continuous on $\mu_{0} \leq \mu \leq \mu_{1}$, it satisfies $c_{0} \leq f \leq c_{1}$ for some positive constants $c_{0}, c_{1}$. Define $C=c_{0} / c_{1}$. Then by the mean value theorem, $a+$ $1 / 2 C^{-1} \cdot(b-a)=a+c_{1}(a-b)^{2} / 2 \cdot \mathrm{c}_{0} \cdot(b-a) \leq a+\int_{a}^{b}(\mu-a) f(\mu) d \mu / \int_{a}^{b} f(\mu) d \mu=\mathrm{M}(a, b)=\mathrm{b}+\int_{a}^{b}(\mu-b) f(\mu) d \mu / \int_{a}^{b} f(\mu) d \mu$ $\leq b-c_{0}(a-b)^{2} / 2 \cdot c_{1} \cdot(b-a)=b-1 / 2 C \cdot(b-a)$.

${ }^{13}$ The insurer's revenue is $\mathrm{p}(\theta) \cdot \int_{a}^{b} f(\eta) d \eta$ and expected benefit cost is $\theta \cdot \int_{a}^{b} \mu f(\mu) d \mu$. 
non-degenerate pool of risk classes, $\mu^{\prime}<\mu<\mu^{\prime \prime}$, where $\mu^{\prime}+\eta$ and $\mu^{\prime \prime}+\eta$ are the slopes at which consumers with these risks are indifferent between B and other offered contracts A and C. The height of B is determined by the breakeven condition $\pi(\theta)=\theta \mathrm{M}\left(\mu^{\prime}, \mu^{\prime \prime}\right) \equiv \theta \mu^{*}$. Introduce a contract $\mathrm{D}$ to the southwest of B on the line with slope $\mu^{*}+\eta$ and above the ray with slope $\mathrm{M}\left(\mu^{\prime}, \mu^{*}\right)$. This contract is better than $\mathrm{B}$ for the consumers with $\mu^{\prime}<\mu<\mu^{*}$, and worse than B for consumers with $\mu^{*}<\mu<\mu^{\prime \prime}$. Then it cherry picks away from $B$ the consumers in the interval $\mu^{\prime}<\mu<\mu^{*}$, and it is profitable since it is above the ray with slope $\mathrm{M}\left(\mu^{\prime}, \mu^{*}\right)$ that determines breakeven for this cherry picked group. Hence, D blocks B. The figure is drawn for discretely separated offered contracts, but the argument also holds when there are continua of offered contracts to the left or right of B. With pooling contracts ruled out, any candidate equilibrium must be separating, with premiums satisfying $\partial \pi(\theta)-\eta=\pi(\theta) / \theta$. This is a differential equation with the boundary condition that the most risky consumers are fully insured, and has the unique solution $\pi(\theta)=\theta\left(\mu_{1}\right.$ $+\eta \cdot \ln (\theta))$ for $\theta_{0} \leq \theta \leq 1$, with $\theta_{0}=\exp \left(-\left(\mu_{1}-\mu_{0}\right) / \eta\right)$. This is the curve between the points $A$ and $B$ in Figure 9. The consumers distribute themselves across contracts so that $\mu=\mu_{1}+\eta \cdot \ln (\theta)$, or $\theta=\exp \left(-\left(\mu_{1}-\mu\right) / \eta\right)$. Now consider introduction of a new contract $\mathrm{D}$ at $\theta=1$ with a premium $\pi^{*}<\pi(1)$. This will attract the pool of consumers who were previously located at $\theta$ between the coverage $\theta^{\prime}$ at point $B$ and 1 , or with risks between $\mu^{\prime}=\mu_{1}+\eta \cdot \ln \left(\theta^{\prime}\right)$ and $\mu_{1}$, where $\theta^{\prime}$ and $\pi^{*}$ are related by the formula $\pi^{*}=\mu_{1}+\eta \cdot \ln \left(\theta^{\prime}\right)+\left(1-\theta^{\prime}\right) \eta$. This pool has average risk $M\left(\mu^{\prime}, \mu_{1}\right)$. When $D$ is above the ray with slope $M\left(\mu^{\prime}, \mu_{1}\right)$, as shown in the figure, it is profitable and blocks C. But this configuration must hold when $\theta^{\prime}$ is close enough to 1 , since $\pi^{*}=\mu_{1}$ $O\left(\left(1-\theta^{\prime}\right)^{2}\right)$ by expansion of the log, while $\mathrm{M}\left(\mu^{\prime}, \mu_{1}\right) \leq \mu_{1}-1 / 2 C\left(1-\theta^{\prime}\right)$ for some $C>0$ from the properties of the conditional expectation (see fn. 11), so that $\pi^{*}-\mathrm{M}\left(\mu^{\prime}, \mu_{1}\right)=c\left(1-\theta^{\prime}\right)-O\left(\left(1-\theta^{\prime}\right)^{2}\right)>0$ for $1-\theta^{\prime}$ sufficiently small. This demonstration is for particular preferences, but the result holds more generally; see Riley (1976).

\section{FIGURE 9 ABOUT HERE}

Now consider the effect of creditable scope regulation. Suppose regulation allows a single contract $\theta$, and there are no enrollment mandates or premium subsidies. If $\mathrm{M}\left(\mu_{0}, \mu_{1}\right) \leq \mu_{0}+\eta$, then risk aversion is sufficiently strong so that all consumers enroll, there is no adverse selection, and full insurance with $\theta=1$ and $\pi(1)=\mathrm{M}\left(\mu_{0}, \mu_{1}\right)$ is Pareto optimal. Alternatively, if $\mathrm{M}\left(\mu_{0}, \mu_{1}\right)>\mu_{0}+\eta$, there exists a minimum $\mu^{\prime}>\mu_{0}$ independent of $\theta$ satisfying $\eta=M\left(\mu^{\prime}, \mu_{1}\right)$ - $\mu^{\prime}$; existence of this minimum is guaranteed since the right-hand-side of this condition is continuous in $\mu^{\prime}$, exceeds $\eta$ at $\mu^{\prime}=\mu_{0}$, and is zero at $\mu^{\prime}=\mu_{1}$. Any

consumer with $\mu>\mu^{\prime}$ then has $\mu+\eta>\mathrm{M}\left(\mu^{\prime}, \mu_{1}\right)$, and will choose to buy any contract $\theta$ with premium $\theta \cdot \mathrm{M}\left(\mu^{\prime}, \mu_{1}\right)$, and vice versa. Then the break even condition $\pi(\theta) / \theta=\mathrm{M}\left(\mu^{\prime}, \mu_{1}\right)$ can be met for any $\theta>0$, and 
in particular met for full insurance $\theta=1$ and the premium $\pi(1)=M\left(\mu^{\prime}, \mu_{1}\right)$. Then a creditable scope restriction to full insurance is second-best Pareto optimal. This model is obviously special, but it illustrates a broader principle: Standardized contracts are not necessarily subject to as stark a trade-off between level of insurance and non-enrollment of the healthy as is found in markets where contract terms are unregulated.

An alternative to a single allowed contract under creditable coverage regulation is to permit several contracts with different levels of scope. For example, the configuration in Figure 8 with discrete contracts A, B, C will separate the population into pools. This can be stable if regulation forbids introduction of contracts like $\mathrm{D}$ that are just below $\mathrm{B}$ in coverage and cherry pick its lowest risk enrollees. At least in the simple model we have used to investigate scope regulation, one can calculate for any distribution of risks $\mu$ the viability and stability of market equilibrium, and contract market shares, for any candidate menu of allowed contracts. In general, clear separation of the contracts allowed under creditable coverage is required to avoid unraveling. Contracts with moderate coverage are needed to achieve high enrollment if there is no enrollment mandate, but contracts with very low coverage have to be excluded to avoid socially unacceptable levels of "underinsurance”. Of course, premium support and/or enrollment mandates will attract or force people into the contracts allowed under creditable coverage regulation, and relax the constraints on achieving a socially acceptable stable market.

Consumer Misperceptions and Scope Regulation: If consumers misperceive their own preferences, then their choices may not be in their self-interest, but more seriously may contribute to adverse selection and health insurance market failure. Two behavioral tendencies, observed in laboratory and field experiments, are overconfidence in beliefs, and errors in estimating probabilities of future events, particularly rare events in the remote future. Thus, people are unrealistically sure of themselves when making guesses about facts such as the length of the Amazon River or the expected length of their remaining healthy life, and when judging future low-probability risks, often either overstate them or treat them as if they have probability zero. In the context of health insurance, these tendencies may lead consumers to undervalue protection against risk, evaluate insurance contracts primarily in terms of expected net payoff, and underestimate the expected net payoff relative to actuarial reality.

In the context of coverage scope, individuals may differ in the risks they perceive of developing different conditions, and the certitude with which they hold these perceptions, and these behavioral heterogeneities can have a substantial impact on adverse selection and the stability of the market. In our model of choice of coverage scope and creditable regulation of scope in the health insurance market, it is easy to examine the impact of consumer misperceptions of risk, and the relation between true risk and the degree of risk aversion. Previously, $\mu$ was assumed to be both the actual and perceived risk of an 
individual, and $\eta$ was treated as constant and unrelated to $\mu$. More generally, the gap $\mu^{*}-\mu$ between perceived risk $\mu^{*}$ and true risk $\mu$ can be noisy, and may be correlated with $\mu$. In addition, the certainty equivalent value of eliminating risk, which can be written $\eta=\alpha \sigma^{2} / 2$, where $\alpha$ is a coefficient of absolute risk aversion and $\sigma^{2}$ is the variance of health losses from all causes, may be distorted if consumers belief's about $\sigma^{2}$ are unrealistically low, and may be correlated with $\mu$ if the degree of risk aversion is correlated with risk.

In the presence of these behavioral effects, the consumer will choose coverage scope among offered contracts to maximize $\theta\left(\mu^{*}+\eta\right)-\pi(\theta)=\theta\left(\mu+\left[\eta-\mu+\mu^{*}\right]\right)-\pi(\theta)$. Then, if consumers underestimate their true risk, $\mu^{*}<\mu$, this effectively lowers the certainty equivalent value of eliminating risk, and moves them toward a knife edge judgment on whether a contract is actuarially fair. Underestimating $\sigma^{2}$ also moves consumers toward this knife edge. The worst case for adverse selection is $\mu^{*}<\mu$ and the gap largest when $\mu$ is small, as in this case healthy consumers are less inclined to insure, particularly with contracts whose premiums are determined by a pool of more risky enrollees. On the other hand, if there is a negative correlation of $\alpha$ and $\mu$, so that healthy consumers are more risk adverse, this will increase their willingness to enroll and introduce an advantageous selection offset to the adverse selection induced by private information. If $\mu^{*}$ is random and uncorrelated with $\mu$, then private beliefs do not induce behavior that is related to $\mu$, and there are no selection effects, adverse or advantageous. Adverse selection rises with an increasing positive correlation of $\mu$ and $\mu^{*}$, and an increasing mean for the gap $\mu-\mu^{*}$. There is controversy about the appropriateness of government intervention to nudge consumers toward choices that reflect their true rather than perceived risk situations. However, there is a case for intervention if consumers as a result of these misperceptions impose external costs on society, say by failing to insure and falling back on the government as an "insurer of last resort", even under the ideology that government should respect consumer sovereignty and not try to “second-guess” and manipulate consumers.

\section{CONCLUSIONS}

It is clear that in the United States, the current “dog's breakfast” of incentives and regulations, and the behavior of participants in response to these regulations, have not resulted in an efficient, equitable health care system. In comparison with other developed countries, the U.S. population pays far too much, in private and public funds combined, for the final health outcomes achieved, and there are large gaps and inequities in outcomes. We conclude from our overview that the general health insurance market in the United States has been substantially damaged by unraveling and inefficient screening. If private insurance markets, such as those envisioned in the Patient Protection and Affordable Care Act (PPACA), are the 
politically determined preference for organization of health insurance in the U.S., then it is critical to regulate these markets to achieve workable competition and equitable and efficient outcomes.

We conclude that the State-level health insurance exchanges planned under the PPACA can be protected from market failure by carefully designed standardized contracts and creditable coverage regulation used in tandem with some combination of premium subsidies, risk adjustment, and enrollment mandates. We have previously mentioned Switzerland as a model of successful implementation in a strongly market-oriented economy of mandatory health insurance with legislated creditable coverage requirements, offered through private insurers; see Newhouse (1996) and Heiss-McFadden-Winter (2008). If enrollment mandates were removed as a policy tool in the United States, State exchanges would remain a viable mechanism for offering insurance contracts that would attract most consumers and reduce free-riding by the uninsured, provided creditable coverage regulations and premium subsidies were used to protect the market from destabilizing cherry-picking and reduce the relative attractiveness of self-insurance to the lowest-risk consumers. There is a largely successful U.S. precedent for this form of regulation, with about 92 percent enrollment without enrollment mandates in the Medicare Part D market for prescription drug insurance introduced by the Bush administration in 2006. That said, enrollment mandates are a useful policy tool that substitute for premium subsidies, reduce the public cost of meeting the objectives of the PPACA, and control the externality imposed by consumers who fail to insure and end up with the cost of their health care borne by the public. Further, enrollment mandates seem to fall well within the range of mandates that the United States and member States have imposed on markets and consumers in the past to advance the public good; e.g., safety standards on toys, CAFE standards on automobiles, communicable disease quarantines, compulsory automobile insurance, and the military draft.

This paper has not undertaken a comprehensive analysis of the health care sector that examines the health care delivery system as well as health finance. Finding good mechanisms for provision of health care may place additional requirements on the health insurance market. This breadth of analysis should be a target of future research. 


\section{References}

Abaluck, J. and J. Gruber (2011) Choice inconsistencies among the elderly: evidence from plan choice in the Medicare Part D program, American Economic Review, 101(4), 1180-1210.

Abbring, J., P. Chiappori, J. Heckman, J. Pinquet (2003) Adverse selection and moral hazard in insurance: can dynamic data help to distinguish? Journal of the European Economic Association, 1(2/3), 512-21.

Agarwal, V., J. Ligon (1998) Insurer contract nonperformance in a market with adverse selection, Journal of Risk and Insurance, 65(1), 135-150.

Akerlof, G. (1970) The Market for "Lemons": Quality uncertainty and the market mechanism, The Quarterly Journal of Economics, 84(3): 488-500.

Allard, M., J. Cresta, and J. Rochet (1997) Pooling and separating equilibria in insurance markets with adverse selection and distribution costs, Geneva Papers on Risk and Insurance-Theory, 22(2), 103.120.

Arrow, K. (1963) Uncertainty and the Welfare Economics of Medical Care. American Economic Review, 53:941-973.

Bajari, P., H. Hong, A. Khwaja (2006), Moral hazard, adverse selection, and health expenditures: a semiparametric analysis, NBER Working Paper 12445.

Belli, P. (2001) How adverse selection affects the health insurance market, World Bank Policy Research Working Paper 2574.

Blouin, M. (2003) Equilibrium in a decentralized market with adverse selection, Economic Theory, 22(2), 245-262.

Blumberg, L., J. Holahan (2009) The Individual Mandate - An Affordable and Fair Approach to Achieving Universal Coverage, New England Journal of Medicine, 361 (1): 6-7.

Boccuti, C. and M. Moon (2003) Adverse selection in private stand-alone drug plans and techniques to reduce it, Commonwealth Club white paper.

Buchmueller, T. (2008) Community rating, entry-age rating, and adverse selection in private health insurance in Australia, Geneva Papers on Risk and Insurance- Issues and Practice, 33(4), 588-609.

Bunce, V., J. Wieske (2010) Health Insurance Mandates in the States 2010, white paper, Council for Affordable Health Insurance.

Card, D, C. Dobkin, N. Maestas (2008) The impact of nearly universal insurance coverage on health care utilization: evidence from Medicare, NBER working paper 10365.

Cardon, J., Hendel, I. (2001) Asymmetric information in health insurance: evidence from the National Medical Expenditure Survey, Rand Journal of Economics 32 (3): 408-427.

Chade, H., E. Schlee (2011) Optimal insurance with adverse selection, Theoretical Economics.

Chade, H., V. de Serio (2002) Risk Aversion, Moral Hazard, and the Principal's Loss, Economic Theory, Vol. 20(2), 637-644

Chiappori, P. (2000). Econometric Models of Insurance under Asymmetric Information, Handbook of Insurance, Georges Dionne (ed), 365-394.

Chiappori, P., B. Jullien, B. Salanie, F. Salanie (2006) Asymmetric information in insurance: general testable implications, working paper.

Chiappori, P.; Salanie, B. (2000) Testing for Asymmetric Information in Insurance Markets, Journal of Political Economy 108 (1): 56-78.

Cho, I., and D. Kreps (1987) Signaling games and stable equilibria,. Quarterly Journal of Economics, 102(2), 179-221.

Clark, J. (1895) The gold standard of currency in the light of recent theory, Political Science Quarterly, 10(3), 389-403. 
Clark, R. (1976) The soundness of financial intermediaries, Yale Law Journal, 86(1), 1-102.

Copernicus, N. (1519) Modus cudendi monetam, NCT Archives.

Crocker, K., and A. Snow (1985a) A simple tax structure for competitive equilibrium and redistribution in insurance markets with asymmetric information, Southern Economic Journal, 51(4), 1142-1150.

Crocker, K., and A. Snow (1985b) The efficiency of competitive equilibria in insurance markets with asymmetric information, Journal of Public Economics, 26(2), 207.219.

Crosby, Everett (1905). Fire prevention, Annals of the American Academy of Political and Social Science (American Academy of Political and Social Science) 26 (2): 224-238.

Cutler, D. and R. Zeckhauser (2000) The anatomy of health insurance, in A. Culyer and J. Newhouse (eds) Handbook of Health Economics, Elsevier Science, Chap. 11.

Cutler, D. and S. Reber (1998), Paying for health insurance: the trade-off between competition and adverse selection, Quarterly Journal of Economics, 113(2), 433-466.

Cutler, D., A. Finkelstein, and K. McGarry (2008) Preference heterogeneity and insurance markets: explaining a puzzle of insurance, American Economic Review, 98(2), 157-162..

Dahlby, B. (1981) Adverse selection and Pareto improvements through compulsory insurance, Public Choice, 37(3), 547.558.

Dasgupta, P., and E. Maskin (1986) The existence of equilibrium in discontinuous economic games, II: Applications, The Review of Economic Studies, 53(1), 27.41.

De Donder, P., J. Hindriks (2006) Equilibrium social insurance with policy-motivated parties, Core Discussion Paper 2006/33.

De Meza, D. and D. Webb (2001), Advantageous selection in insurance markets, RAND Journal of Economics, 32(2), 249-262.

Diamond, P. (1978), Welfare analysis of imperfect information equilibrium, Bell Journal of Economics, 9(1), 82-105.

Dionne, G., N. Doherty, and N. Fombaron (2001) Adverse Selection in Insurance Markets, Handbook of Insurance, Chapter 7, p. 185.

Duffie, D. and K. Singleton (2003). Credit Risk: Pricing, Measurement, and Management. Princeton University Press Encinosa,W. (2001) A comment on Neudeck and Podczeck, Journal of Health Economics, 20(4), 667.673.

Englehardt, G. and J. Gruber (2011) Medicare Part D and the Financial Protection of the Elderly, American Economic Journal: Economic Policy, 3(4), 77-102.

Fagart, M., and B. Kambia-Chopin (2006): .Prevention in insurance markets, Annales d.Economie et de Statistique, 82, 55.70 .

Fang, H., M. Keane, and D. Silverman (2008), Sources of advantageous selection: evidence from the medigap insurance market, Journal of Political Economy, 116(2), 303-350.

Feldman, R., C. Escribano, and L. Pellisé (1998): .The role of government in health insurance markets with adverse selection, Health Economics, 7(8), 659.670.

Feldstein, M. (1973), Welfare loss of excess health insurance, Journal of Political Economy, 81(2), 251-280.

Finkelstein, A. (2002) When can partial public insurance produce Pareto improvements?,.NBER Working Paper.

Finkelstein, A. (2004) Minimum standards, insurance regulation and adverse selection: evidence from the Medigap market, Journal of Public Economics, 88(12), 2515.2547.

Finkelstein, A.; McGarry, K. (2006). Multiple dimensions of private information: evidence from the long-term care insurance market, American Economic Review 96 (4): 938-958. 
Finkelstein, A.; Poterba, J. (2004). "Adverse selection in insurance markets: policyholder evidence from the UK annuity market". Journal of Political Economy 112 (1): 183-208.

Finkelstein, A., Poterba, J., and Rothschild, C, (2009), "Redistribution by insurance market regulation: Analyzing a ban on gender-based retirement annuities”, Journal of Financial Economics 91, 38-58

Gale, D. (1992) A Walrasian theory of markets with adverse selection, Review of Economic Studies, 59(2), 229-255.

Gale, D. (1996) Equilibria and Pareto optima of markets with adverse selection, Economic Theory, 7(2), 207-235.

Glazer, J., and T. McGuire (2000): .Optimal risk adjustment in markets with adverse selection: an application to managed care, American Economic Review, 90(4), 1055.1071.

Grennan, M. (2012) Price discrimination and bargaining: empirical evidence from medical devices, American

Economic review, forthcoming.

Gresham, T. (1558) letter to Queen Elisabeth I.

Grossman, H. (1979): .Adverse selection, dissembling, and competitive equilibrium, The Bell Journal of Economics, 10(1), 336.343.

Grubel, H. (1971) Risk, uncertainty, and moral hazard, Journal of Risk and Insurance, 38(1), 99-106.

Gruber, J. (2008) Covering the uninsured in the United states, Journal of Economic Literature, 46(3), 571-606.

Heiss, F., D. McFadden, and J. Winter (2006): Who failed to enroll in Medicare Part D, and why? Early results. Health Affairs, 25, w344-w354.

Heiss, F., D. McFadden, and J. Winter (2009): Regulation of health insurance markets: Lessons from enrollment, plan choice, and adverse selection in Medicare Part D. NBER Working Paper No. 15392.

Heiss, F., D. McFadden, and J. Winter (2010): Mind the gap! Consumer perceptions and choices of Medicare Part D prescription drug plans. In D. A. Wise (Ed.), Research Findings in the Economics of Aging, 413-481. Chicago and London: Chicago University Press.

Heiss, F., D. McFadden, and J. Winter (2011): The demand for Medicare Part D prescription drug coverage: Evidence from four waves of the Retirement Perspectives Survey. In D. A. Wise (Ed.), Explorations in the Economics of Aging, 159-182. Chicago and London: Chicago University Press.

Hellwig, M. (1987): .Some recent developments in the theory of competition in markets with adverse selection, European Economic Review, 31(1-2), 319.325.

Hendel, I. (2005) Efficient sorting in a dynamic adverse-selection market, Review of Economic Studies, 72(2), 467-497.

Hendren, N. (2011) Private information and insurance rejections, MIT working paper.

Herring, B., M. Pauly (2006) The effect of State community rating reulation on premiums and coverage in the individual health insurance market, NBER working paper 12504.

Hodgeman, D. (1960) Credit risk and credit rationing, Quarterly Journal of Economics, 74 (2), 258-278.

Holmstrom, B. (1979), "Moral hazard and observability". Bell Journal of Economics, pp. 74-91.

Johnson, W. (1977) Choice of compulsory insurance schemes under adverse selection, Public Choice, 31, 23-35.

Keating, R. (2012) Health Care Policy Cost Index 2012, white paper, Small Business \& entrepreneurship Council.

Kilburn, F. (1904) Control and supervision of trust companies, Annals of the American Academy of Political and Social Science, 24, 29-42.

Lopez-Cunat, J. (2000) Adverse selection under ignorance, Economic Theory, 16(2), 379-399.

Mahdavi, G. (2005) Advantageous selection versus adverse selection in life insurance market, Japanese Society for the Promotion of Science. 
Mahul, O., B. Wright (2004) Implications of incomplete performance for optimal insurance, Economics, New Series, 71(284), 661-670.

Mailath,, G., G. Noldeke (2008) Does competitive pricing cause market breakdown under extreme adverse selection? Journal of Economic Theory 140, 97 - 125.

McFadden, D., C. Noton, and P. Olivella (2012) Minimum coverage in insurance markets, working paper.

McFadden, D., J. Winter, F. Heiss (2008) Consumer directed health care: Can consumers take care of themselves?, Swiss Journal of Economics and Statistics, 144(3), 285-307.

McGuire, T. (2000) Physician agency, in A. Culyer and J. Newhouse (eds) Handbook of Health Economics, Elsivier Science, Chap. 9.

Mimra, W., and A. Wambach (2011) A Game-Theoretic Foundation for the Wilson Equilibrium in Competitive Insurance Markets with Adverse Selection,.CESifo Working Paper Series.

Miyazaki, H. (1977) The rat race and internal labor markets, The Bell Journal of Economics, 8(2), 394.418.

Mott, D. et al (1998) Agency theory, drug formularies, and drug product selection: implications for public policy, Journal of Public Policy and Marketing, 17(2), 287-293.

Neudeck, W., and K. Podczeck (1996) Adverse selection and regulation in health insurance markets, Journal of Health Economics, 15(4), 387-408.

Neuhaus, W. (1995) "Community rating and equalisation", ASTIN Bulletin 25 (2), 95-118.

Olivella, P., and M. Vera-Hernandez (2010) How complex are the contracts offered by health plans? Journal of the Spanish Economic Association, 1(3), 305-323.

Olivella, P., and M. Vera-Hernández, (2012) “Testing for asymmetric information in private health insurance”, The Economic Journal, forthcoming.

Olivella, P., and M. Vera-Hernández (2007) "Competition among Differentiated Health Plans under Adverse Selection", Journal of Health Economics, 26, 233-250.

Pauly, M. (1970) The welfare economics of community rating, Journal of Risk and Insurance, 37(3), 407-18.

Pauly, M. (1974) Overinsurance and the public provision of insurance: the roles of moral hazard and adverse selection, Quarterly Journal of Economics, 88(1), 44-62.

Pauly, M. and S. Nicholson (1999) Adverse consequences of adverse selection, Journal of Health Politics, Policy, and Law, 24(5), 921-930.

Radner, R. (1968) Competitive equilibrium under uncertainty, Econometrica, 36, 31-58.

Radner, R. (1970) Problems in the theory of markets under uncertainty, American Economic Review, 59(2), 454-460.

Riley, J. (1975) Competitive signaling, Journal of Economic Theory, 10, 174-186.

Riley, J. (1979) Informational Equilibrium, Econometrica, 47(2), 331-359.

Riley, J. (2002) Weak and strong signals, Scandinavian Journal of Economics, 104(2), 213-236.

Rose, C. (1993) Equilibrium and adverse selection, RAND Journal of Economics, 24(4), 559-569.

Rothschild, M., and J. Stiglitz (1976) Equilibrium in competitive insurance markets: An essay on the economics of imperfect information, Quarterly Journal of Economics, 90(4), 629.649.

Sharpe, William F. (1964). Capital asset prices: A theory of market equilibrium under conditions of risk, Journal of Finance, 19 (3), 425-442

Smart, M. (2000) Competitive insurance markets with two unobservables, International Economic Review, 41(1), 153.170. 
Spence, M. (1974) Competitive and optimal response to signals, Journal of Economic Theory, 7(3), 296-332.

Spence, M. (1976) Informational aspects of market structure, Quarterly Journal of Economics, 90(4), 591-597.

Spence, M. (1978) Product differentiation and performance in insurance markets, Journal of Public Economics, 10(3), 427-447.

Spence, M., R. Zeckhauser (1971) Insurance, information, and individual action, American Economic Review, 61(2), 380-387.

Villeneuve, B. (2000) The consequences for a monopolistic insurance firm of evaluating risk better than customers: the adverse selection hypothesis reversed, Geneva Papers on Risk and Insurance-Theory, 25(1), 65.79.

Walford, C. et al (1881) On the Number of Deaths from Accident, Negligence, Violence, and Misadventure in the United Kingdom and some other Countries, Journal of the Royal Statistical Society.

Wilson, C. (1977) A model of insurance markets with incomplete information, Journal of Economic Theory, 16(2), 167-207.

Wilson, C. (1979) Equilibrium and adverse selection, American Economic Review, 69(2), 313-317.

Wilson, C. (1980) The nature of equilibrium in markets with adverse selection, Bell Journal of Economics, 11(1), 108-130.

Zweifel, P., F. Breyer, M. Kifmann (2009) Health Economics, Springer-Verlag: Berlin. 


\section{Remedies for Sick Insurance - Tables and Figures}

Table 1. Regulatory Mechanisms for Health Insurance Markets

\section{Consumer regulation}

\begin{tabular}{|l|l|}
\hline & mandates that consumers buy creditable coverage \\
\hline & direct or tax-linked premium subsidies \\
\hline & low-income premium subsidies \\
\hline Provider regulation \\
\hline & payment capitation \\
\hline & risk-adjusted outcome-based payment \\
\hline & approval or review of diagnostic classifications and treatment assignments \\
\hline Insurer regulation \\
\hline & Franchising and entry controls \\
\hline & capitalization and reserve requirements \\
\hline & rate-of-return or premium load regulation \\
\hline & controls on screening, enrollment, and recission \\
\hline & limits on underwriting \\
\hline & minimum coverage requirements for offered contracts \\
\hline & oversight of benefit payments \\
\hline & ex ante risk adjustment or ex post experience adjustment with public or mutual subsidies \\
\hline & public premium subsidies \\
\hline & \\
\hline &
\end{tabular}


Table 2. State-Level Coverage Mandates for Employer-Provided and Subsidized Health Insurance

\begin{tabular}{|c|c|c|c|}
\hline Condition with Coverage Mandate & $\begin{array}{l}\text { Number } \\
\text { of States }\end{array}$ & Condition with Coverage Mandate & $\begin{array}{l}\text { Number } \\
\text { of States }\end{array}$ \\
\hline AIDS/HIV Testing/Vaccine & 10 & HPV Vaccine & 11 \\
\hline Alcoholism/Substance Abuse & 46 & Hormone Replacement Therapy & 4 \\
\hline Alzheimer's & 4 & In Vitro Fertilization & 15 \\
\hline Ambulatory Surgery Centers & 13 & Kidney Disease & 2 \\
\hline Ambulance Transportation & 13 & Long-Term Care & 5 \\
\hline Ambulatory Cancer Treatment & 3 & Lyme Disease & 3 \\
\hline Anti-Psychotic Drugs & 10 & Lymph Edema & 3 \\
\hline Asthma Education \& Self-Management & 3 & Mammography Screening & 50 \\
\hline Attention Deficit Disorder & 2 & Mastectomy \& Minimum Stay & 25 \\
\hline Autism & 25 & Maternity & 22 \\
\hline Bilateral Cochlear Implant & 2 & Maternity Minimum Stay & 50 \\
\hline Blood Lead Poisonng Screening & 8 & Mental Health General & 42 \\
\hline Blood Products & 3 & Mental Health Parity & 48 \\
\hline Bone Marrow Transplant & 9 & Minimum Hysterectomy Stay & 2 \\
\hline Bone Mass Measurement & 16 & Morbid Obesity Treatment & 7 \\
\hline Brain Injury & 3 & Neurodevelopment Therapy & 1 \\
\hline Breast Reduction & 1 & Newborn Hearing Screening & 18 \\
\hline Breast Reconstruction & 50 & Newborn Sickle Cell Anemia Testing & 4 \\
\hline Cancer Pain Medication Therapies & 7 & Off-Label Drug Use & 36 \\
\hline Cervical Cancer / HPV Screening & 31 & Oriental Medicine & 3 \\
\hline Chemotherapy & 8 & Orthotic and/or Prosthetics & 19 \\
\hline Circumcision & 1 & Ostomy Procedure and Supplies & 1 \\
\hline Chlamydia Screening & 4 & Ovarian Cancer Screening & 7 \\
\hline Cleft Lip and Palate & 17 & PKU/Metabolic Disorder & 33 \\
\hline Clinical Trial (cancer) & 28 & Port-Wine Stain Elimination & 2 \\
\hline Colorectal Cancer Screening & 34 & Prescription Drugs & 4 \\
\hline Congential Bleeding Disorder & 3 & Prescription Inhalent & 2 \\
\hline Congenital Defect/Habilatative Service & 6 & Prostate Cancer Screening & 36 \\
\hline Contraceptive & 29 & Psychotropic Drugs & 5 \\
\hline Dental Anesthesia & 31 & Reconstructive Surgery & 7 \\
\hline Developmental Disability & 1 & Rehabilitative Service & 6 \\
\hline Diabetic Self-Management & 38 & Residential Crisis Service & 3 \\
\hline Diabetic Supplies & 47 & Second Surgical Opinion & 10 \\
\hline Drug Abuse Treatment & 34 & Shingles (Herpes Zoster) Vaccine & 1 \\
\hline Early Intervention Service & 7 & Smoking Cessation & 6 \\
\hline Emergency Room Service & 45 & Special Footwear & 2 \\
\hline Hair Prosthesis & 10 & Telemedicine & 9 \\
\hline Hearing Aids for Minor & 17 & TMJ Disorder & 19 \\
\hline Heart Transplant & 1 & Varicose Vein Removal & 1 \\
\hline Home Health Care & 20 & Vision Care Service & 1 \\
\hline Hospice Care & 12 & Well Child Care & 33 \\
\hline
\end{tabular}

Source: Bunce and Weske (2010) 
Figure 1. Expected Utility Maximization under Health Uncertainty

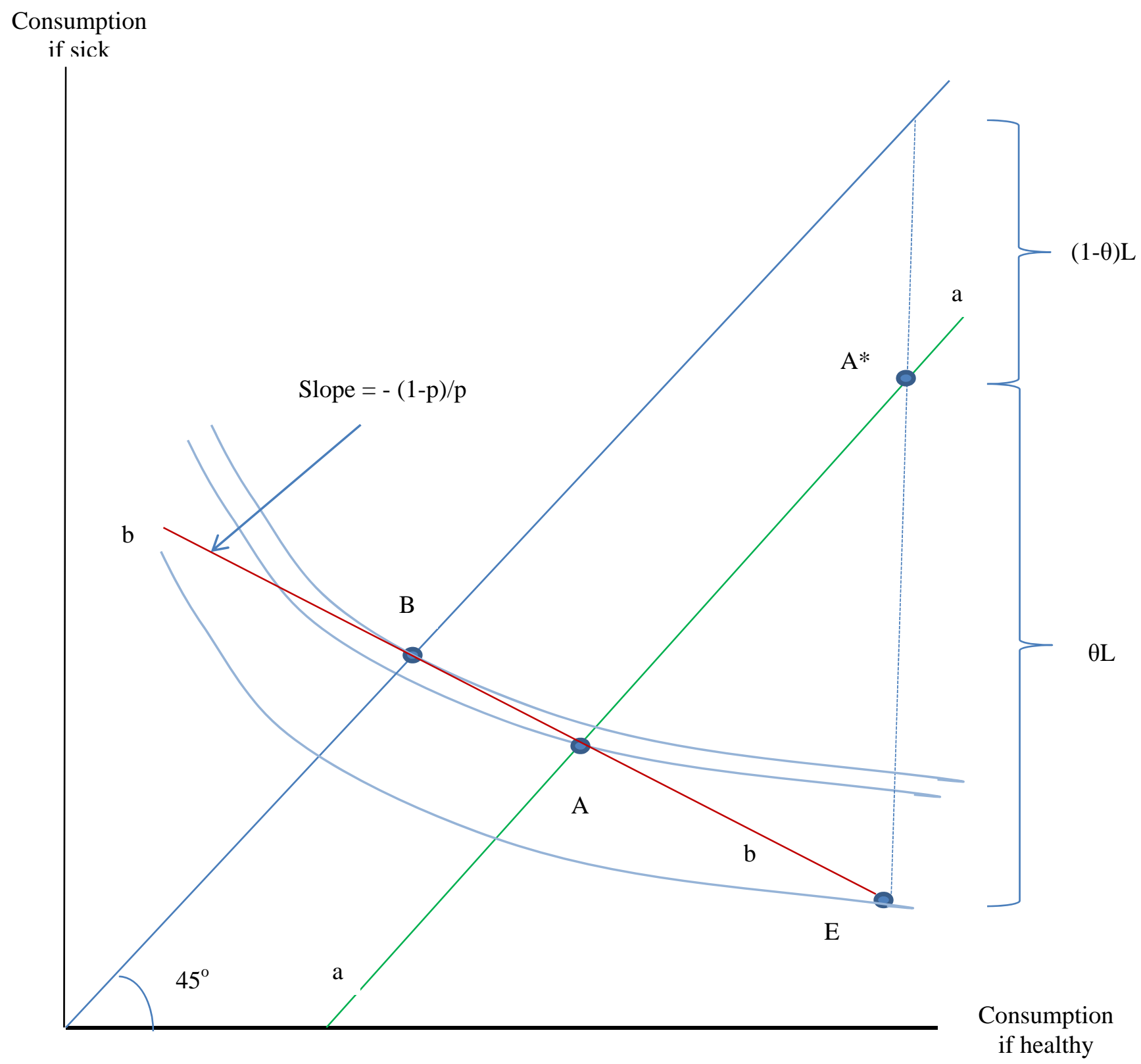


Figure 2. Two Consumer Risk Classes

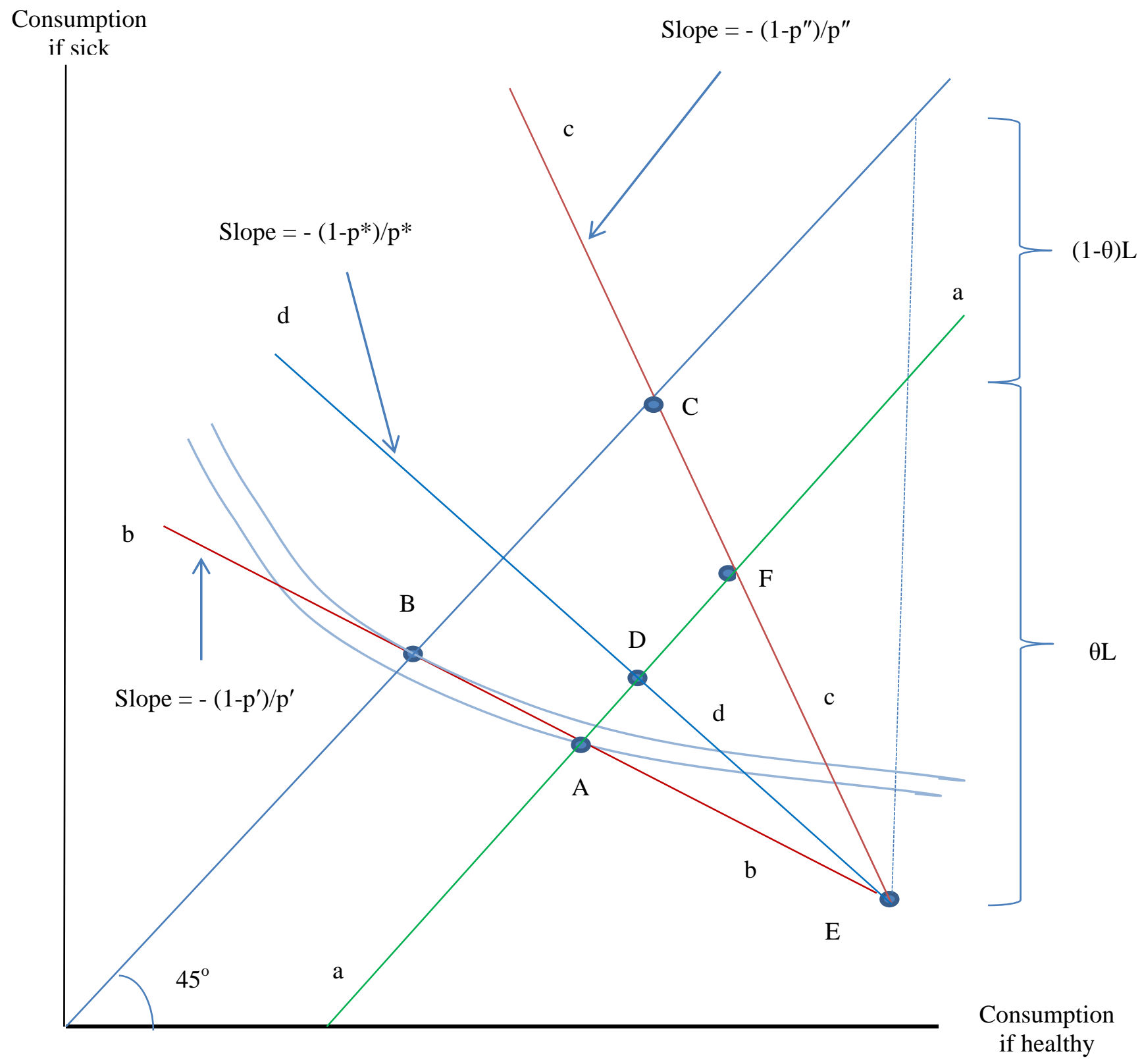


Figure 3. Pooled Contract Blocked by Cherry-Picking Alternative

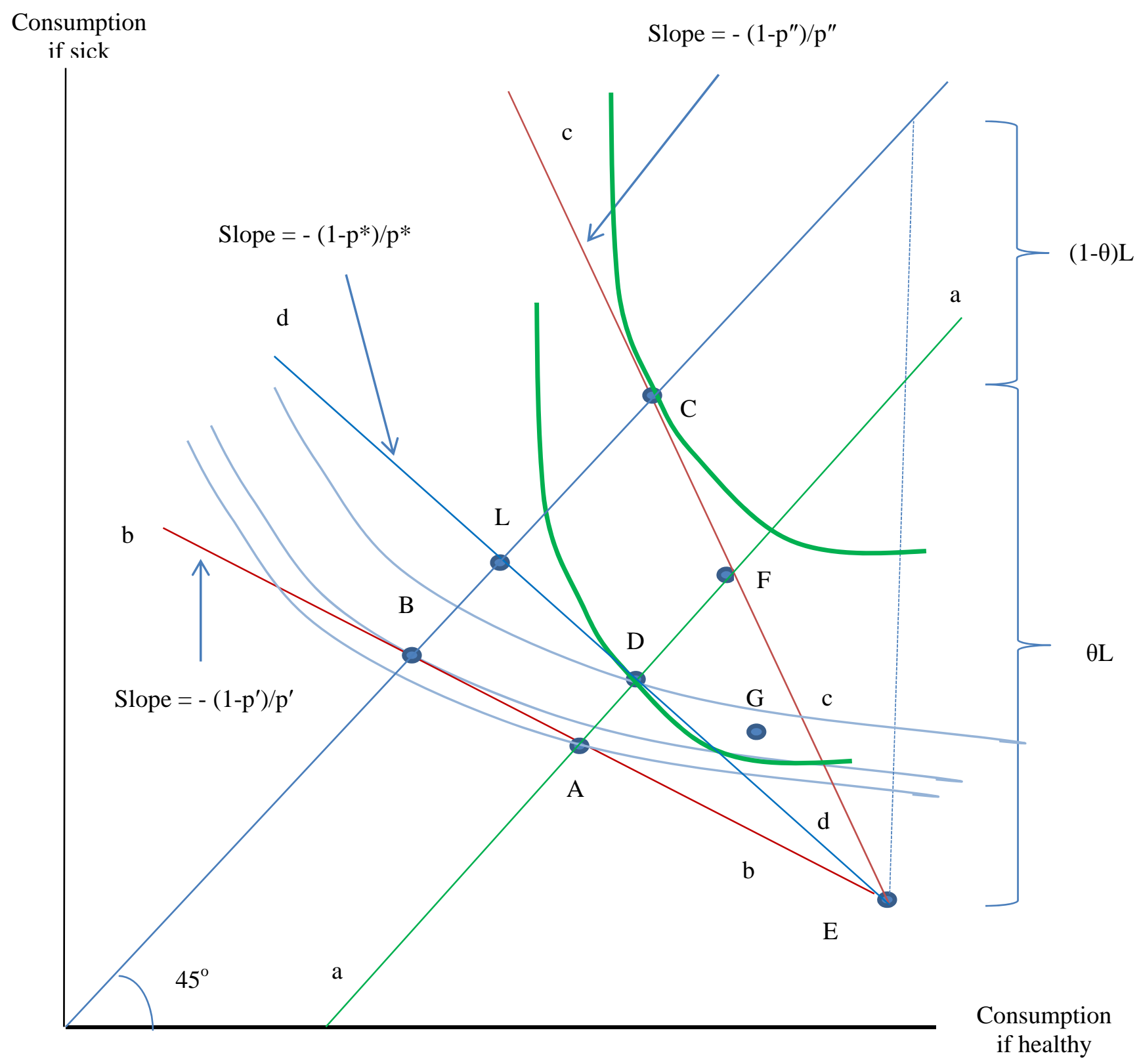


Figure 4. Separating Equilibrium

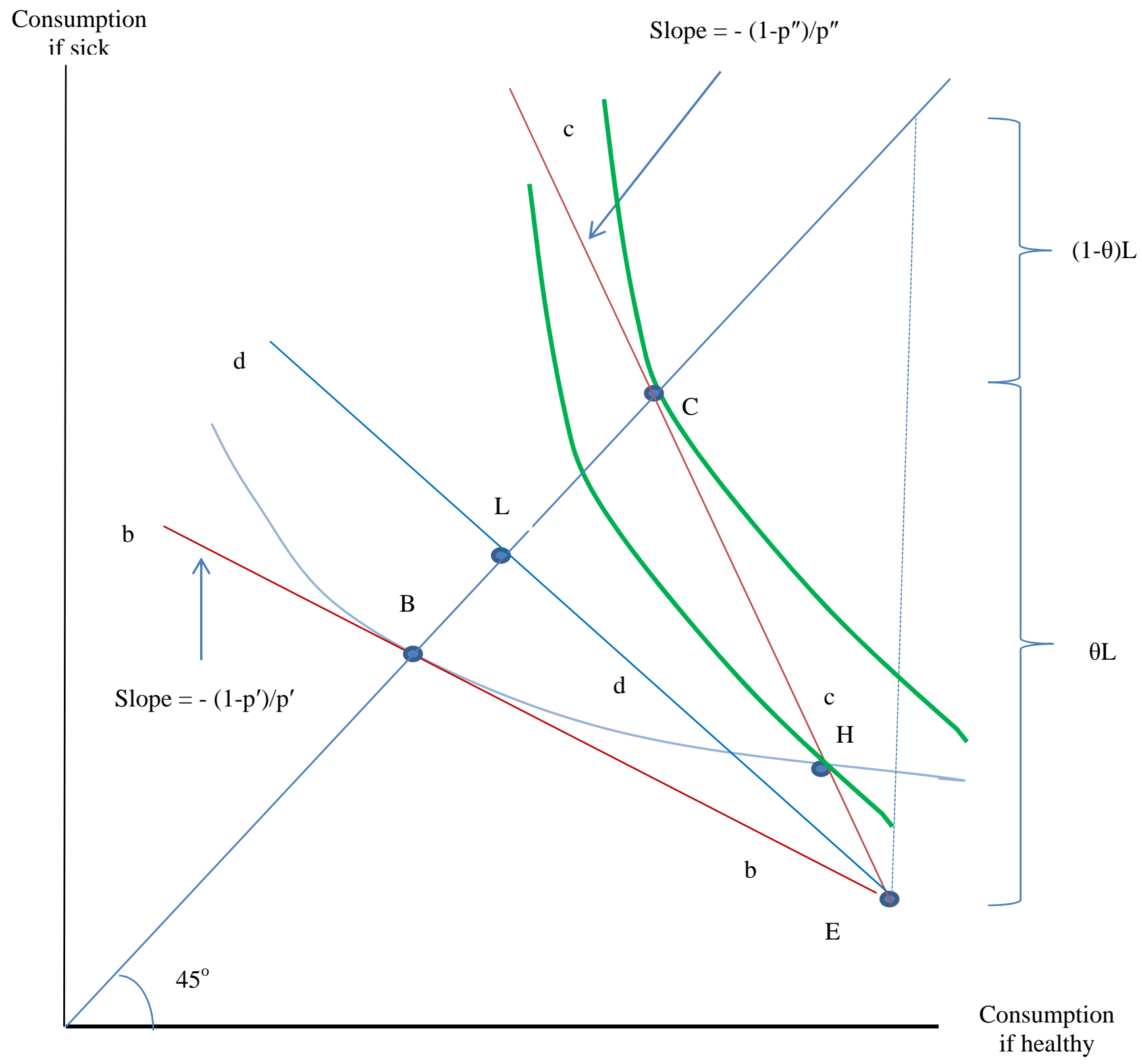


Figure 5. Creditable Coverage Regulation with Supplements

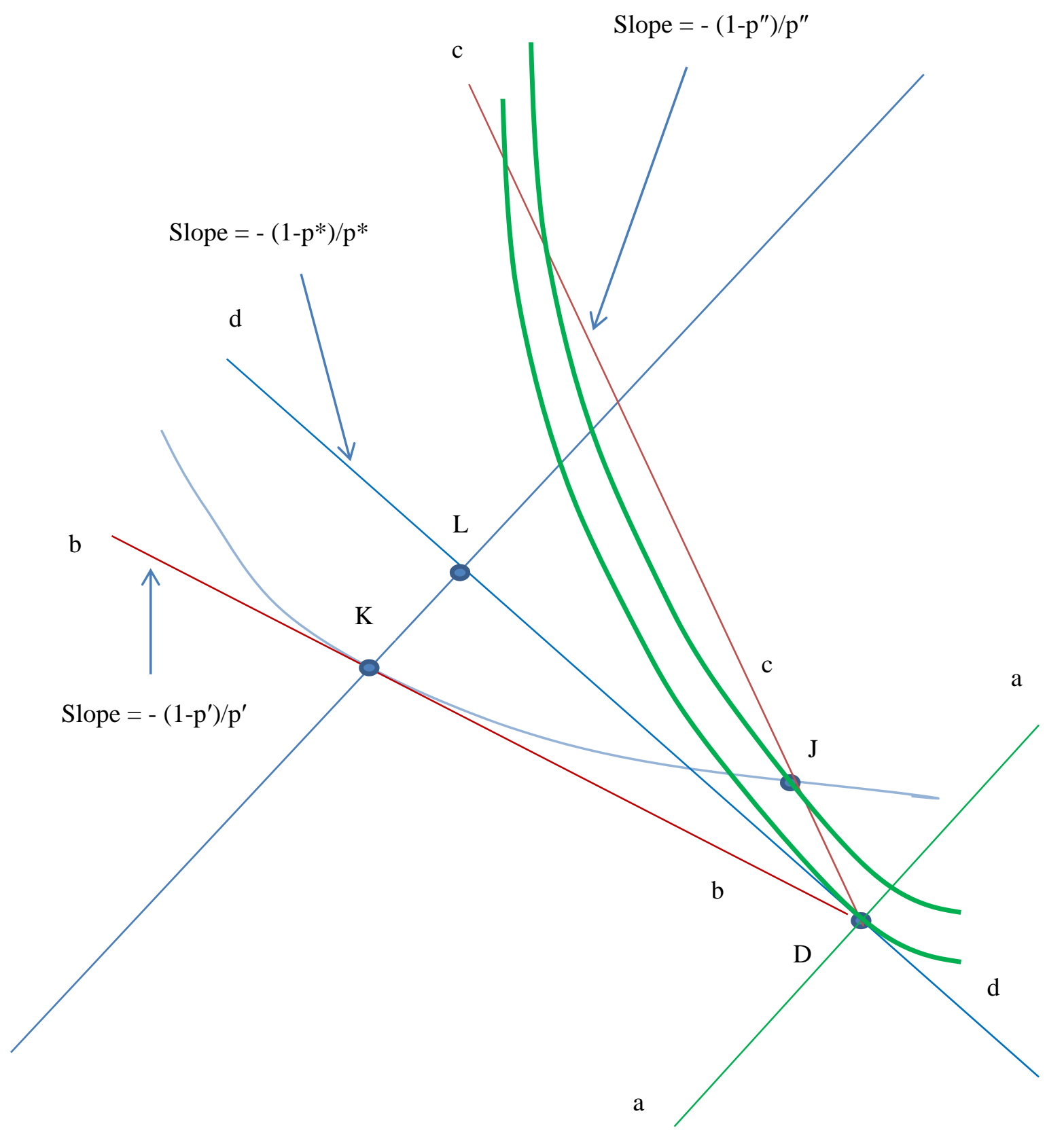


Figure 6. Premium Subsidies

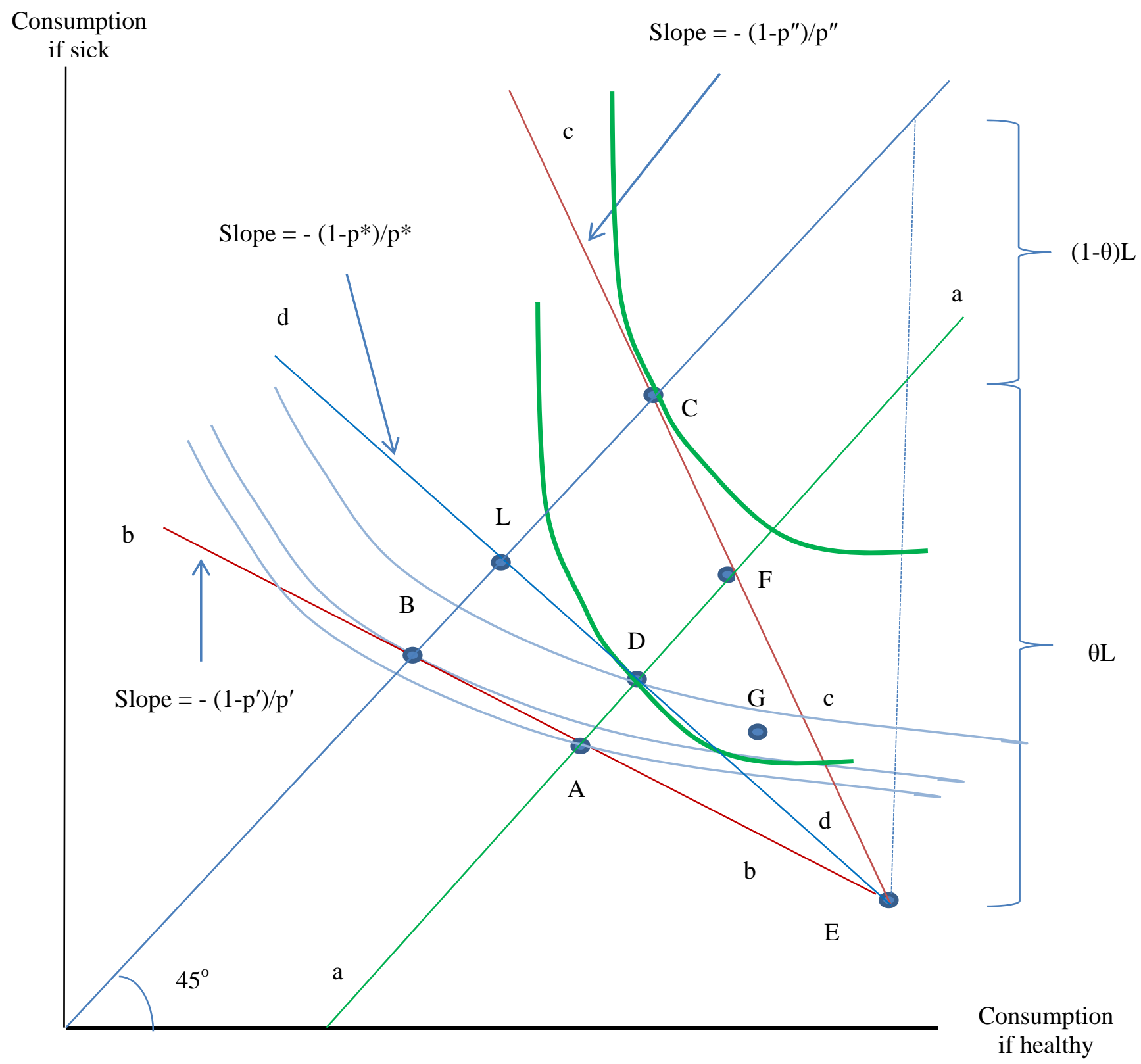


Figure 7. The Market for Contract Scope

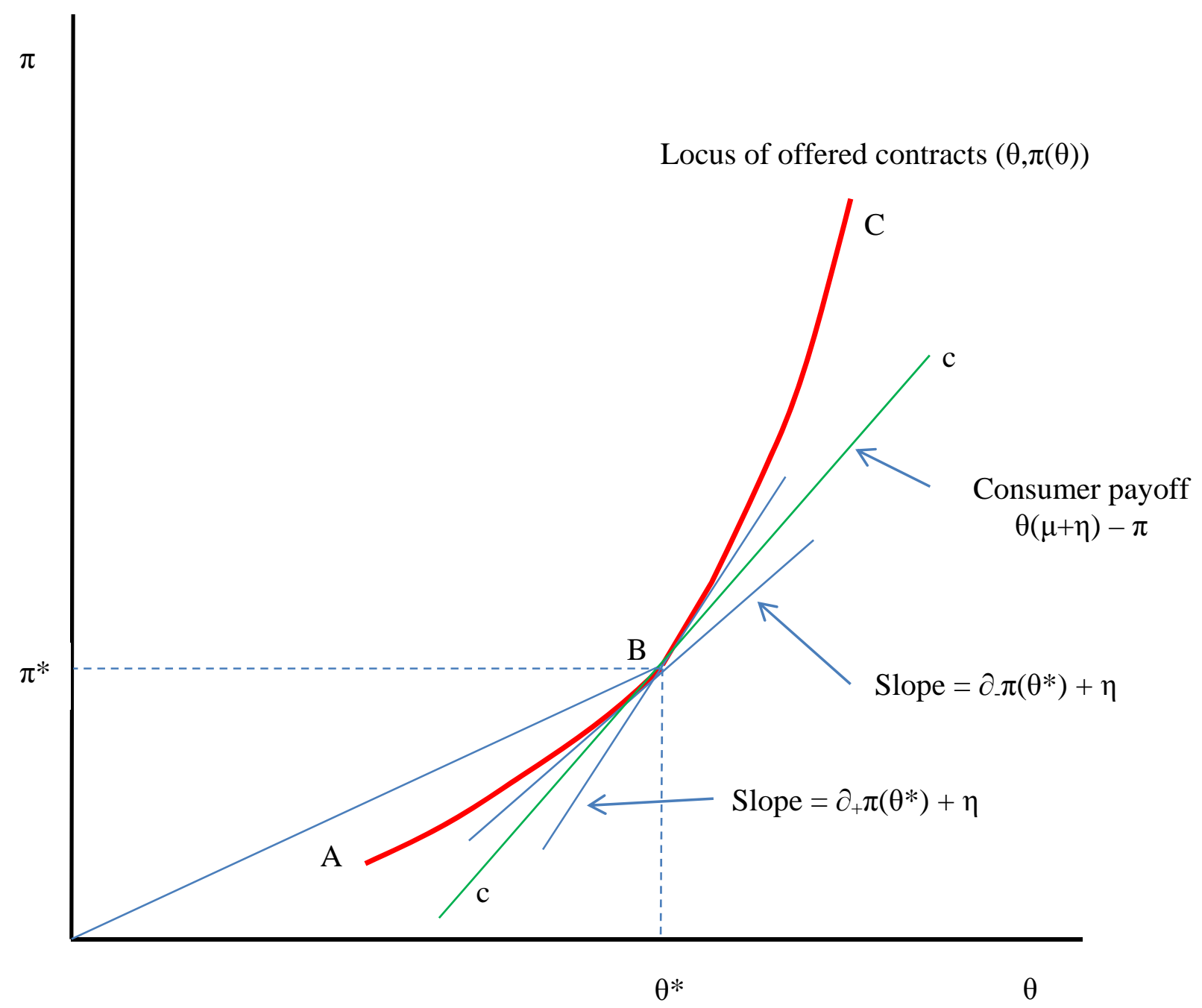


Figure 8. Pooling Contracts are Blocked

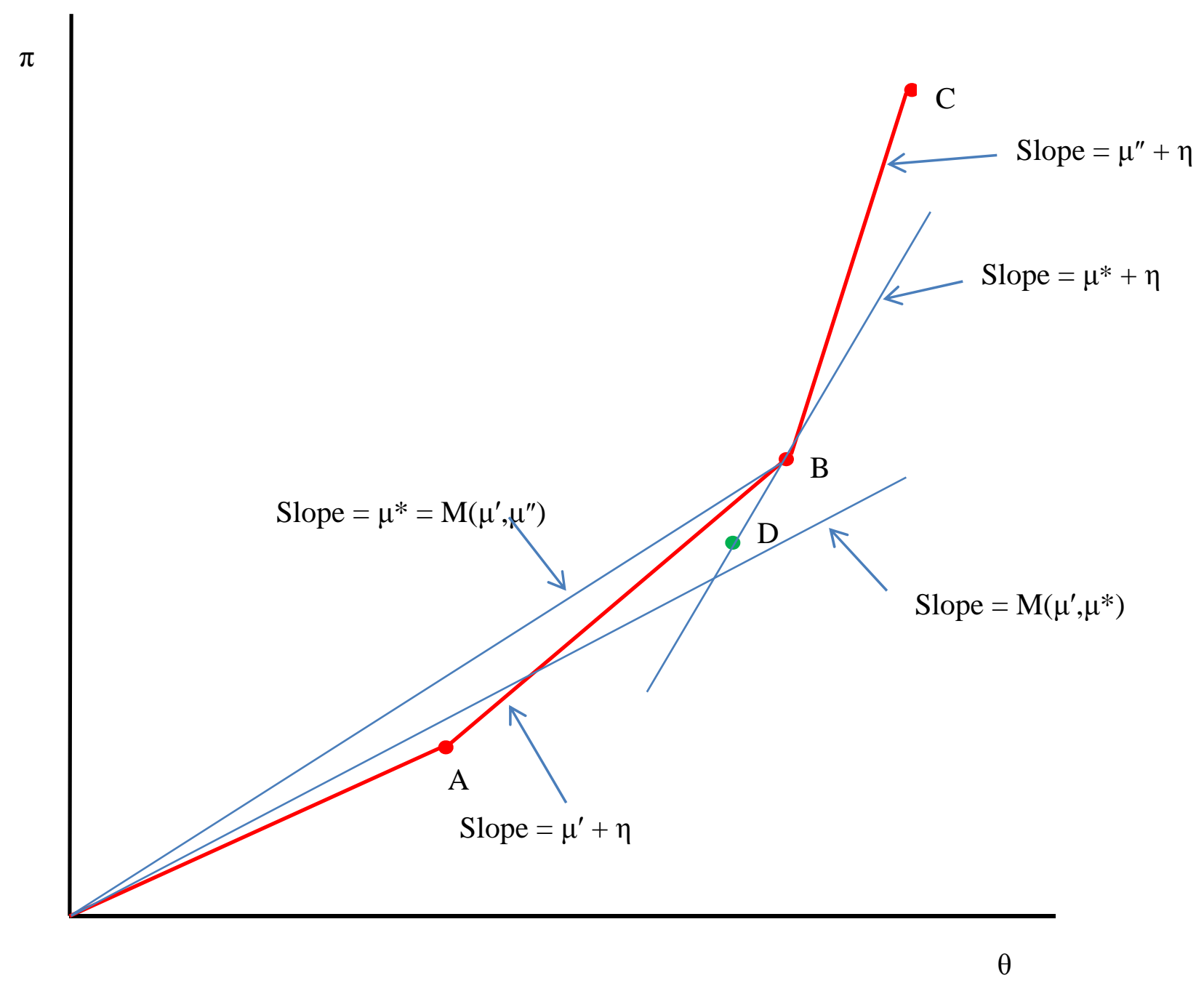


Figure 9. Separating Contracts are Blocked

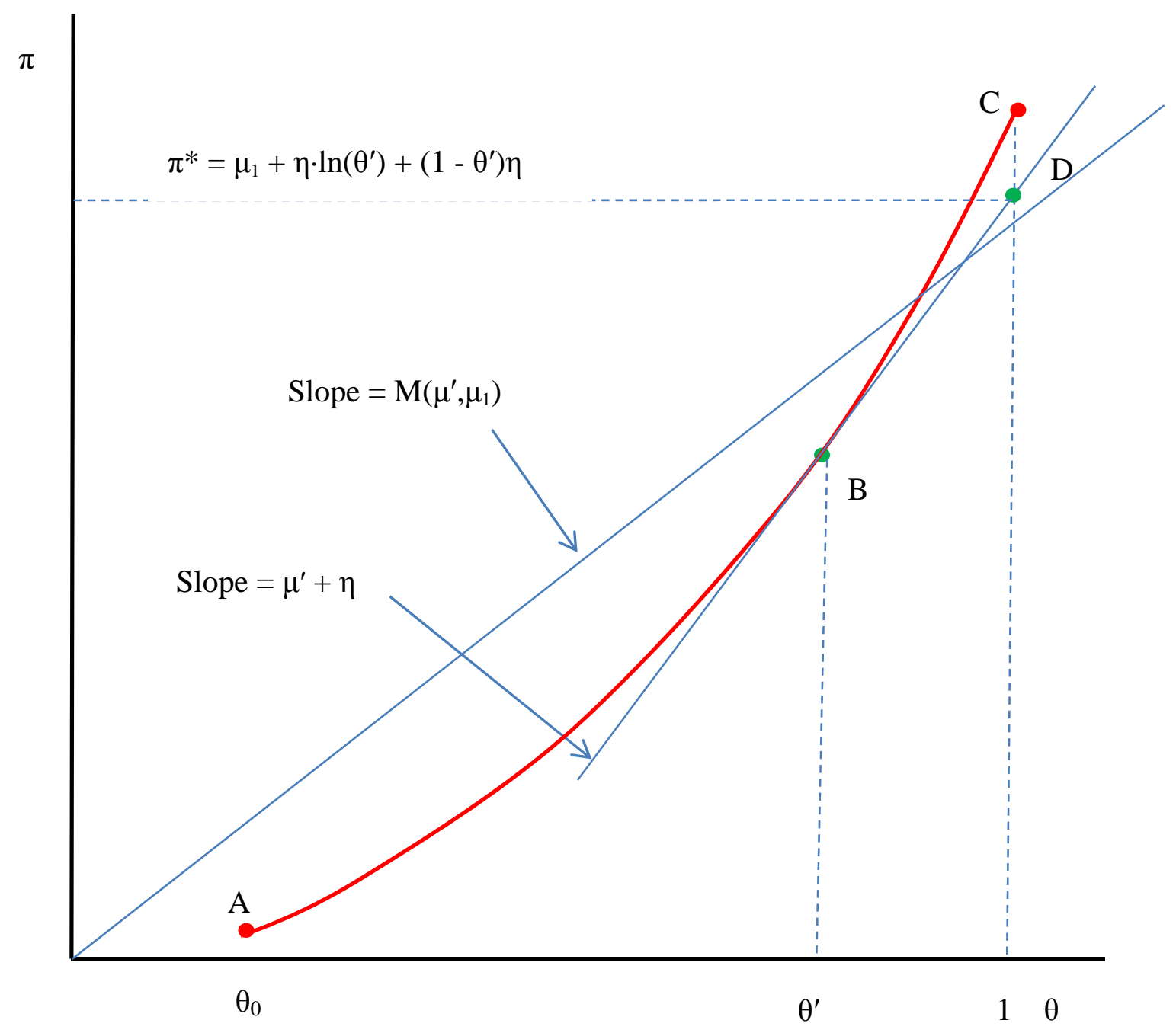

